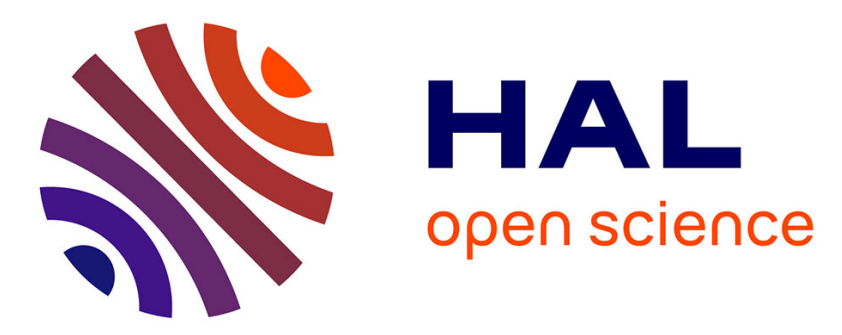

\title{
Influence of the North Atlantic SST Variability on the Atmospheric Circulation during the Twentieth Century
}

Guillaume Gastineau, Claude Frankignoul

\section{To cite this version:}

Guillaume Gastineau, Claude Frankignoul. Influence of the North Atlantic SST Variability on the Atmospheric Circulation during the Twentieth Century. Journal of Climate, 2015, 28 (4), pp.13961416. 10.1175/JCLI-D-14-00424.1 . hal-01122524

\section{HAL Id: hal-01122524 \\ https://hal.sorbonne-universite.fr/hal-01122524}

Submitted on 4 Mar 2015

HAL is a multi-disciplinary open access archive for the deposit and dissemination of scientific research documents, whether they are published or not. The documents may come from teaching and research institutions in France or abroad, or from public or private research centers.
L'archive ouverte pluridisciplinaire HAL, est destinée au dépôt et à la diffusion de documents scientifiques de niveau recherche, publiés ou non, émanant des établissements d'enseignement et de recherche français ou étrangers, des laboratoires publics ou privés. 


\title{
Influence of the North Atlantic SST Variability on the Atmospheric Circulation during the Twentieth Century
}

\author{
Guillaume Gastineau and Claude Frankignoul \\ LOCEAN Laboratory, Sorbonne Universités-UPMC, CNRS, IRD, and MNHN, Paris, France
}

(Manuscript received 16 June 2014, in final form 2 October 2014)

\begin{abstract}
The ocean-atmosphere coupling in the North Atlantic is investigated during the twentieth century using maximum covariance analysis of sea surface temperature (SST) and 500-hPa geopotential height analyses and performing regressions on dynamical diagnostics such as Eady growth rate, wave activity flux, and velocity potential. The North Atlantic Oscillation (NAO) generates the so-called SST anomaly tripole. A rather similar SST anomaly tripole, with the subpolar anomaly displaced to the east and a more contracted subtropical anomaly, which is referred to as the North Atlantic horseshoe pattern, in turn influences the atmosphere. In the fall and early winter, the response is NAO like and primarily results from subpolar forcing centered over the Labrador Sea and off Newfoundland. In summer, the largest atmospheric response to SST resembles the east Atlantic pattern and results from a combination of subpolar and tropical forcing. To emphasize the interannual to multidecadal variability, the same analysis is repeated after low-pass filtering. The SST influence is dominated by the Atlantic multidecadal oscillation (AMO), which also has a horseshoe shape, but with larger amplitude in the subpolar basin. A warm AMO phase leads to an atmospheric warming limited to the lower troposphere in summer, while it leads to a negative phase of the NAO in winter. The winter influence of the AMO is suggested to be primarily forced by the Atlantic SSTs in the northern subtropics. Such influence of the AMO is found in winter instead of early winter because the winter SST anomalies have a larger persistence, presumably because of SST reemergence.
\end{abstract}

\section{Introduction}

The sea surface temperature (SST) in the North Atlantic sector shows much variability at low frequencies. In the instrumental record, the North Atlantic basin experiences alternating basinwide warming and cooling with an approximate periodicity of $70 \mathrm{yr}$, known as Atlantic multidecadal oscillation (AMO). Different paleoproxies confirm the presence of such multidecadal variability with a periodicity ranging from 20 to $70 \mathrm{yr}$ (Kilbourne et al. 2008; Sicre et al. 2008; Knudsen et al. 2011). The AMO has been related to the Atlantic meridional overturning circulation (AMOC). In climate model simulations without any external forcing, an intensification of the AMOC is accompanied by a larger northward ocean heat transport that leads to a warm AMO phase a few years later (Knight et al. 2005; Marini and Frankignoul 2013).

Corresponding author address: Guillaume Gastineau, LOCEAN/ IPSL, Université Pierre et Marie Curie, 4 Place Jussieu, 75005 Paris, France.

E-mail: guillaume.gastineau@upmc.fr
At seasonal to interannual time scales, the North Atlantic Oscillation (NAO) mainly forces the North Atlantic SST. The NAO is the first mode of atmospheric variability over the North Atlantic region (Hurrell et al. 2003), with the largest variability in the cold season. The NAO is closely linked to the northern annular mode (NAM) and is largely caused by internal tropospheric processes and zonal eddy mean flow interaction (DeWeaver and Nigam 2000; Franzke et al. 2004; Thompson et al. 2003). The NAO generates SST anomalies mainly by turbulent heat exchanges, although advection by anomalous Ekman currents is important near the Gulf Stream and the North Atlantic Current, and mixed layer changes play a role in the subpolar regions (Cayan 1992; see review by Deser et al. 2010). A positive NAO is followed by positive SST anomalies in the western subtropical North Atlantic and negative SST anomalies in the subpolar gyre and off the eastern coast of North Africa, referred to as the SST "tripole," with an opposite phase for a negative NAO. In early winter, the NAO also responds to slightly different tripolar SST anomalies, the North Atlantic SST horseshoe (NAH) 
pattern, thus further amplifying the NAO and acting as a positive feedback (Czaja and Frankignoul 1999, 2002; Watanabe and Kimoto 2000a; Drévillon et al. 2001). The NAH is broadly similar to the tripole, but the subpolar SST anomaly is displaced eastward, and the subtropical anomaly is more contracted, so that there is a crescent-shaped anomaly joining the subpolar and the tropical poles on the eastern Atlantic. Such SST influence has also been found in sensitivity studies with atmospheric models (Kushnir et al. 2002; Peng et al. 2003; Deser et al. 2007). The SST anomalies imprinted by the NAO during the cold season can also reemerge the following fall when the mixed layer deepens (Watanabe and Kimoto 2000b; Timlin et al. 2002; de Coëtlogon and Frankignoul 2003), which may again influence the NAO (Cassou et al. 2007).

Whether such active ocean-atmosphere coupling has a significant influence on the decadal climate variability has been mostly investigated using climate models. Compared to the NAH, the AMO spatial pattern has a larger amplitude in the subpolar region and no anomaly along the Gulf Stream and the North Atlantic Current. Although the North Atlantic Ocean seems to be mostly passive in many climate models (e.g., Delworth and Greatbatch 2000; Dong and Sutton 2005), two-way ocean-atmosphere interactions in the North Atlantic can be the dominant players, as in Timmermann et al. (1998). Gastineau and Frankignoul (2012) showed that AMOC intensification and the associated subpolar warming lead to a negative NAO in winter in six climate models, but Frankignoul et al. (2013) found an opposite atmospheric response in Community Climate System Model, version 3 (CCSM3), so that coupled models fail to simulate a consistent AMOC response in winter. In the observations, a positive correlation at interannual and longer time scales between the AMO and the NAH anomaly that precedes the NAO was also found in Gastineau et al. (2013). During the warm season, the AMO was reported to have a large influence for the precipitation (Sutton and Hodson 2005), especially in northeastern Brazil (Folland et al. 2001), the U.S. Great Plains (Enfield et al. 2001; McCabe et al. 2004; Nigam et al. 2011), and Sahel (Knight et al. 2006; Mohino et al. 2011), and it was also related to hurricane activity (Goldenberg et al. 2001). The AMO impacts in winter have been less studied, although some recent studies showed that the warm AMO phase resulted in more frequent negative NAO, which promotes the occurrence of cold days over Europe and North America (Ting et al. 2011, 2014; Omrani et al. 2014; Peings and Magnusdottir 2014).

However, the relationship and the causality among the North Atlantic SST tripole, NAH, AMO, and atmosphere and the underlying mechanisms are still unclear. Although the instrumental observations cover the period from 1870 to the present day, only two "oscillations" of the AMO occurred, and the quality of atmosphere data in the European sector is limited before the mid-twentieth century, when atmospheric soundings are scarce. Furthermore, other factors influence the atmosphere in the North Atlantic, such as Eurasian snow cover (e.g., Cohen and Jones 2011), Arctic sea ice (e.g., Petoukhov and Semenov 2010; Li and Wang 2013; Frankignoul et al. 2014), or El Niño-Southern Oscillation (Mathieu et al. 2004; Brönnimann et al. 2007). In addition, the anthropogenic and natural external forcings are expected to modify both the NAO and the North Atlantic SST (Stenchikov et al. 2002; Cattiaux and Cassou 2013; Ting et al. 2009; Booth et al. 2012), so that care is needed to distinguish the atmospheric response to North Atlantic SST from the response of both fields to other factors.

In this study, we further document the relationship between North Atlantic SST anomalies and the atmospheric variability and the underlying mechanisms using a reanalysis of the twentieth century. Section 2 presents the data and methods. The ocean-atmosphere interactions at the seasonal scale are discussed in section 3. Section 4 discusses the atmospheric response at the decadal scale. A discussion and conclusions are given in section 5.

\section{Data and methods}

\section{a. Analyzed dataset}

The geopotential height, temperature, zonal and meridional wind, surface pressure, precipitation, and snow cover are retrieved from the NOAA-CIRES Twentieth Century Reanalysis (20CR; Compo et al. 2011). It uses the NCEP GFS atmospheric model with $2^{\circ}$ horizontal resolution and 24 vertical levels, and it is forced with HadISST (Rayner et al. 2003). The 20CR only assimilates surface pressure observations and spans the period from 1870 to 2010, using different atmospheric initial conditions. Both the ensemble mean and the 56 individual members of the $20 \mathrm{CR}$ are considered. The data quality seems limited prior to 1930 , and some data problems were reported before 1966, when the number of assimilated data suddenly increased (Krueger et al. 2013). Therefore, we will consider two periods, 19302010 and 1966-2010. The quasi-biennial oscillation is lacking in $20 \mathrm{CR}$, so that the downward influence from the stratosphere is biased (Paek and Huang 2012). Hence, the role of the stratosphere will be only briefly discussed in the following. The precipitation and snow cover in 20CR are consistent with observations, even 
a) AMO pattern (positive phase)

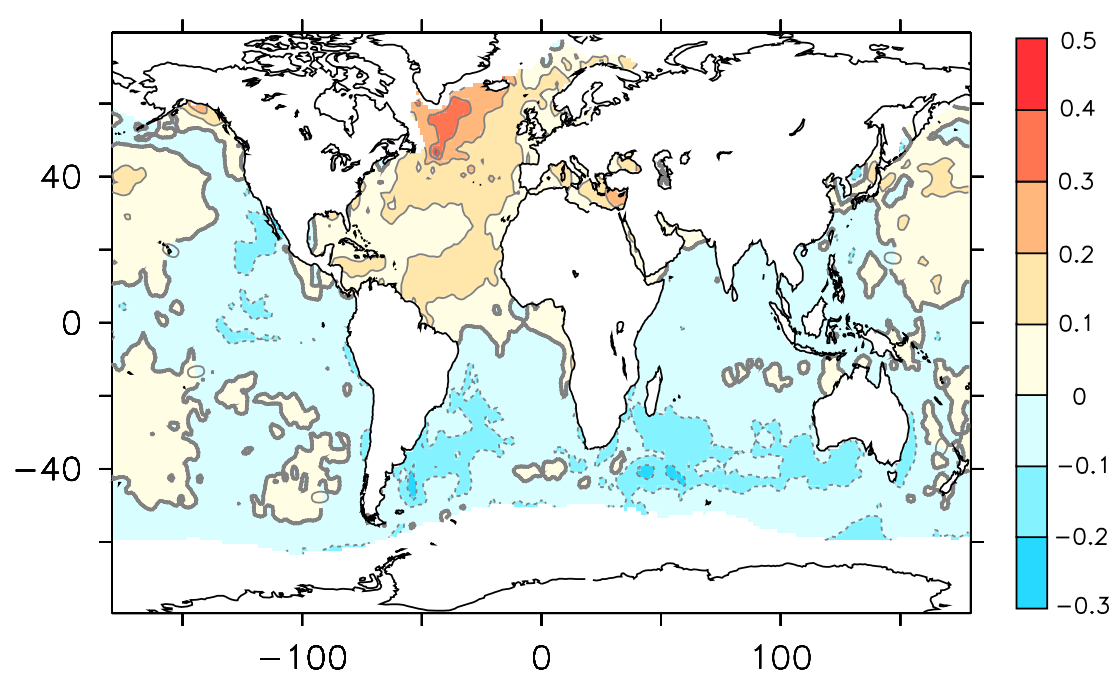

b) Time series

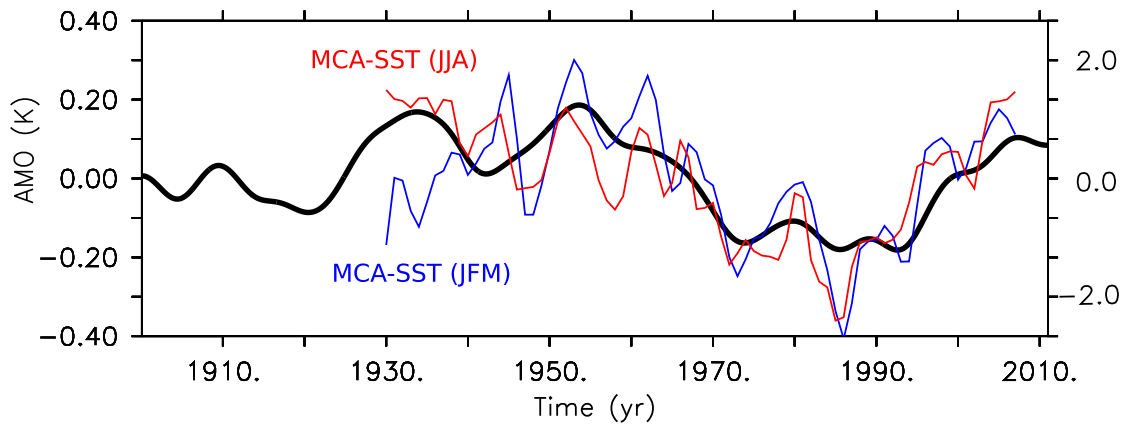

FIG. 1. Pattern of (a) AMO and (b) associated time series (K; thick black line). The AMO is defined by the low-pass-filtered SST averaged over $\left(0^{\circ}-60^{\circ} \mathrm{N}, 80^{\circ} \mathrm{W}-0^{\circ}\right)$ with a 10 -yr cutoff period. In (b), the normalized MCA SST time series leading to the JFM (thin blue line) and JJA (thin red line) atmospheric responses at decadal time scales are also shown.

if the summer precipitation over land has some deficiencies (Lee and Biasutti 2014; Peings et al. 2013). Therefore, we use the GPCP reanalysis (Schneider et al. 2011) instead of 20CR precipitation over land grid points only. For consistency, the HadISST dataset is used for SST and sea ice cover. The regions where the seasonal climatological sea ice coverage exceeds $5 \%$ are excluded from the SST field.

Three-month running means are calculated from the original data and the mean seasonal cycle is removed. To distinguish the internal North Atlantic SST variability from the global warming signal, the regression onto the global-mean SST anomaly (calculated between $60^{\circ} \mathrm{N}$ and $30^{\circ} \mathrm{S}$, without the North Atlantic), smoothed with a low-pass filter with a 3-yr cutoff period, is removed from the SST anomalies. The same procedure cannot be applied to atmospheric variables since the atmosphere responds to both SST forcing and direct atmospheric radiative forcing (Deser and Phillips 2009). Lacking a better model, a third-order polynomial (cubic trend) was removed by least squares fit from all atmospheric data prior to analysis. The AMO index is calculated as the low-pass-filtered SST averaged over the North Atlantic region $\left(0^{\circ}-60^{\circ} \mathrm{N}, 80^{\circ} \mathrm{W}-0^{\circ}\right)$, using a fourth-order Butterworth filter with a 10-yr cutoff (Mann 2008). The AMO time series show a warming starting around 1925, cooling starting around 1965, and warming again in the mid-1990s (Fig. 1). The regression of the global SST onto the normalized AMO index shows the traditional AMO pattern (Ting et al. 2009), with large positive SST anomalies north of $45^{\circ} \mathrm{N}$, and a comma-shaped weak warming extending in the rest of the North Atlantic basin, while cooling is seen in the South Atlantic and Indian Oceans.

\section{b. Maximum covariance analysis}

The main patterns of covariability between the ocean and the atmosphere are estimated with maximum covariance analysis (MCA). The MCA performs a singular 
value decomposition of the covariance matrix between two fields (Bretherton et al. 1992). We use the 500-hPa geopotential height (Z500) anomalies in the North Atlantic sector $\left(20^{\circ}-80^{\circ} \mathrm{N}, 90^{\circ} \mathrm{W}-40^{\circ} \mathrm{E}\right)$ and North Atlantic SST anomalies $\left(10^{\circ}-80^{\circ} \mathrm{N}, 90^{\circ} \mathrm{W}-20^{\circ} \mathrm{E}\right)$. The $500-\mathrm{hPa}$ geopotential height was chosen as it provides a good measure of the tropospheric circulation (Kushnir et al. 2002), but similar results are obtained when using the sea level pressure (SLP) instead of Z500. The results were found to be in most cases largely insensitive to a rotation of the MCA patterns. Each MCA mode is represented by the so-called homogeneous covariance map for one field (regression on the same field time series) when it leads and the heterogeneous covariance map for the other field (regression on the MCA time series of the other field), which preserves orthogonality (Czaja and Frankignoul 2002). Each mode is also characterized by its squared covariance (SC), the squared singular value, and the correlation $(R)$ between the MCA time series of the two fields. The variance fraction (VF) of Z500 (SST) explained by the SST (Z500) is given by the average of the squared heterogeneous correlation map, when the SST (Z500) leads. The MCA time series were standardized (divided by their standard deviation), so that the maps show typical amplitude. In the regression and correlation analysis, the statistical significance is tested with Monte Carlo methods, using 100 permutations of 3-yr blocks for the atmospheric fields to remove the effect of serial autocorrelation. For the MCA, the significance is given by the numbers of randomized SC or correlation that exceed the values being tested.

When the atmosphere leads or is simultaneous with SST, in most cases the MCA primarily reflects the atmospheric forcing of the ocean. As the intrinsic atmospheric persistence is less than 1 month at extratropical latitudes and that of the ocean is much larger, a significant lagged relation between monthly oceanic and atmospheric anomalies when the ocean leads by more than 1 month should indicate an influence of boundary conditions onto the atmosphere. However, persistent tropical teleconnections may induce a lagged correlation between ocean and atmosphere that is not linked to an atmospheric response to the extratropical ocean. Following the method of Frankignoul et al. (2011), we remove these teleconnections from both atmospheric variables and SST by multivariate regression, assuming that they are instantaneous in the atmosphere (which is reasonable for 3-month averages), so that they vary with lag for the SST. The tropical SST is represented by the first three empirical orthogonal functions (EOFs) of the 3-month running averages of SST anomalies between $20^{\circ} \mathrm{S}$ and $20^{\circ} \mathrm{N}$ in the whole tropics, and the regressions are done separately for positive and negative values of the PCs (without removing the respective means) to take into account the asymmetry of tropical-midlatitude teleconnections. As the ENSO teleconnections vary with the season, the regressions are performed separately for each season.

The relations for SST leading the atmosphere will thus be interpreted as reflecting an atmospheric response to SST, unless evidence is found that other concomitant boundary forcing may have contributed to the atmospheric response. As 3-month averages are used to define each calendar month, only lags $\geq 3$ months will be considered to clearly reflect an atmospheric response, with smaller lags being likely contaminated by the atmospheric forcing of the ocean. Note that such large lags are larger than the time needed for the atmosphere to fully respond to SST forcing, which is 1 or 2 months (Deser et al. 2007; Smirnov et al. 2015).

\section{Link between North Atlantic SST anomalies and the atmosphere during the seasonal cycle}

\section{a. Significance and seasonality}

The SC of the first MCA mode between SST anomalies and the ensemble-mean Z500 anomalies and its significance are illustrated as a function of time lag in Fig. 2. The largest SC is obtained in winter during January-March (JFM), when the atmospheric variability is largest and the atmosphere leads the ocean by 1 or 2 months. The covariance decreases at larger lag, but increases again after lag 8 , reflecting the SST reemergence in the fall. Note the small persistence of the SST response to the atmosphere in summer, when the mixed layer is shallow, and the larger covariability in the more recent period 1966-2010. By performing the MCA in moving 20-yr segments from 1870 to 2010 , we found that the SC and the correlation between the two MCA time series is largest from the 1960s onward, which corresponds to a strong increase in the number of assimilated data in 20CR (Krueger et al. 2013). When SST leads the atmosphere, the first two MCA modes are significant in summer (SC of second mode not shown), from May-July (MJJ) to June-August (JJA), and the first one is in fall/ early winter, with a larger SC and significance during 1966-2010. The analysis in this section is, therefore, restricted to this 45 -yr period, as the quality of the earlier data might be insufficient.

\section{b. Summer SST influence}

We first illustrate the lead-lag relation between the summer atmosphere and SST anomalies. When Z500 in JJA leads by 1 month, the first mode shows that an anomaly similar to the east Atlantic pattern (EAP) in 
a) SC (1930-2010)

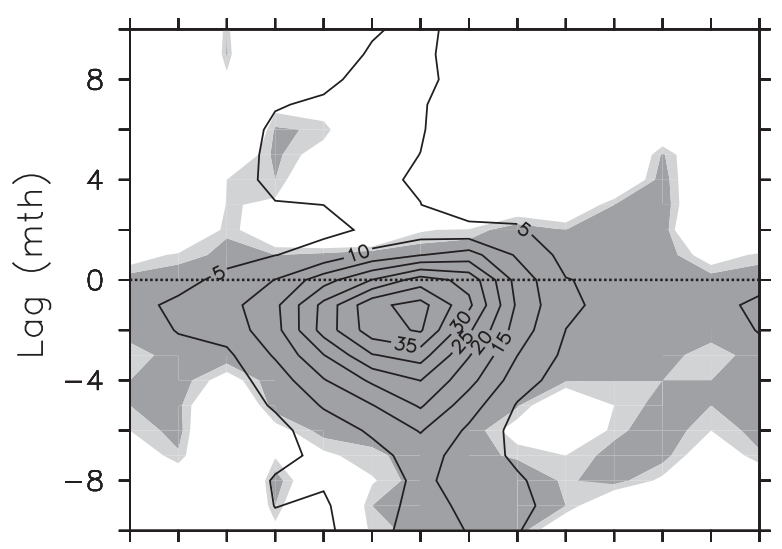

JAS ASO SON OND NDJ DJF JFM FMA MAM AMJ MJJ JJA JAS ASO Z500 (mth)

\section{b) SC (1966-2010)}

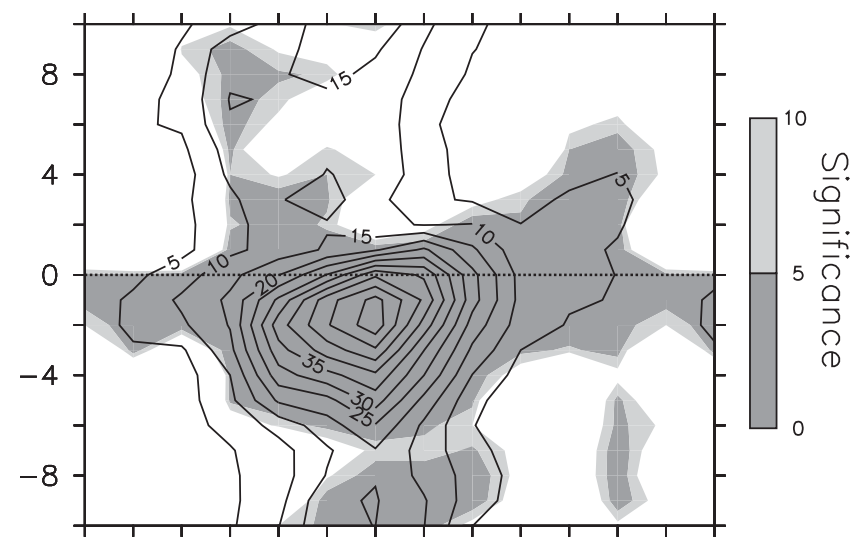

JAS ASO SON OND NDJ DJF JFM FMA MAM AMJ MJJ JJA JAS ASO

Z500 (mth)

FIG. 2. SC $\left(10^{2} \mathrm{hPa}^{2} \mathrm{~K}^{2}\right)$ of the first MCA mode between Z500 and SST using (a) 1930-2010 and (b) only the latest part of the record (1966-2010). The lag (months) is negative (positive) when atmosphere leads (lags). Statistical significance (\%) is indicated by shading.

the atmosphere (Barnston and Livezey 1987) tends to drive a dipolar SST anomaly with a strong warming centered around $50^{\circ} \mathrm{N}, 35^{\circ} \mathrm{W}$ and a cooling north of $60^{\circ} \mathrm{N}$ (Fig. 3a). The second mode shows that anticyclonic perturbations centered between Iceland and the British Isles primarily lead a warming in the eastern North Atlantic and a cooling in the Nordic seas (Fig. 3b).

When Z500 follows SST [lag 3; SST in March-May (MAM)], the first MCA mode indicates that the SST tripole and cooling in the Nordic seas precede an anticyclone over the subpolar North Atlantic during summer, which again resembles the EAP (Fig. 3c). The second mode shows that a more horseshoe-like SST anomaly with a strong cooling in the Gulf Stream/North Atlantic Current region precedes a dipolar geopotential height anomaly resembling a negative phase of the summer NAO (defined as in Folland et al. 2009). To test the robustness of the modes, an MCA was performed for all the 56 members of the 20CR. As illustrated in Figs. 3e and $3 \mathrm{f}$ by the frequency distribution of the SC and $R$ significance at lag 3 (black and red lines, respectively) and by their nearly identical patterns (spatial correlation of the Z500 pattern with that of the 20CR ensemble mean in blue lines), the two modes are very robust among all members. Since the correlation between the MCA time series is about 0.7 , and the cross-validated correlation $R_{\mathrm{CV}}$ is larger than 0.5 (Table 1 ), the spring SST should lead to some useful predictive skill in summer, even if the $\mathrm{Z} 500$ variance fraction explained by the SST is only about $8 \%$.

To investigate whether the atmospheric response in JJA indeed comes from North Atlantic SST forcing, we have estimated the global SST pattern that leads it by 1 month, thus assuming a 1-month atmospheric response time. To do this, the SSTs in MJJ were regressed onto the MCA SST time series so that it shows how the North Atlantic SST used to detect the atmospheric response at lag 3 has evolved in 2 months. For the first mode, illustrated in Fig. $4 a$, the strong warming seen 2 months earlier in Fig. $3 \mathrm{c}$ has persisted in the subpolar regions and only slightly weakened elsewhere in the North Atlantic. The sea ice edge has advanced, reflecting the ocean cooling in the Greenland and Barents Seas (Fig. 4b). Since there are only weak and very localized SST and sea ice cover anomalies in the other basins, we conclude that the atmospheric response is indeed mainly due to the surface conditions in the Atlantic Ocean.

To investigate the influence of SST from the tropics, we performed an MCA for different Atlantic SST domains. An MCA using the pan-Atlantic SST from $20^{\circ} \mathrm{S}$ to $80^{\circ} \mathrm{N}$ provided similar results. To compare the role of extratropical and tropical SST anomalies, we repeated the MCA using SST north of $30^{\circ} \mathrm{N}$ or in the equatorial band $\left(20^{\circ} \mathrm{N}-20^{\circ} \mathrm{S}\right)$. To provide comparable estimates of the covariance when the SST regions differ, we give in Table 1 the normalized squared covariance (NSC), as used by Iwasaka and Wallace (1995),

$$
\mathrm{NSC}=\sqrt{\frac{\mathrm{SC}}{\sum_{i} \sigma_{Z 500_{i}}^{2} \sum_{j} \sigma_{\mathrm{SST}_{j}}^{2}}},
$$

where $\sigma_{Z 500_{i}}$ and $\sigma_{\mathrm{SST}_{j}}$ are the standard deviations of the Z500 and SST anomalies at the $i$ th and $j$ th grid points, 


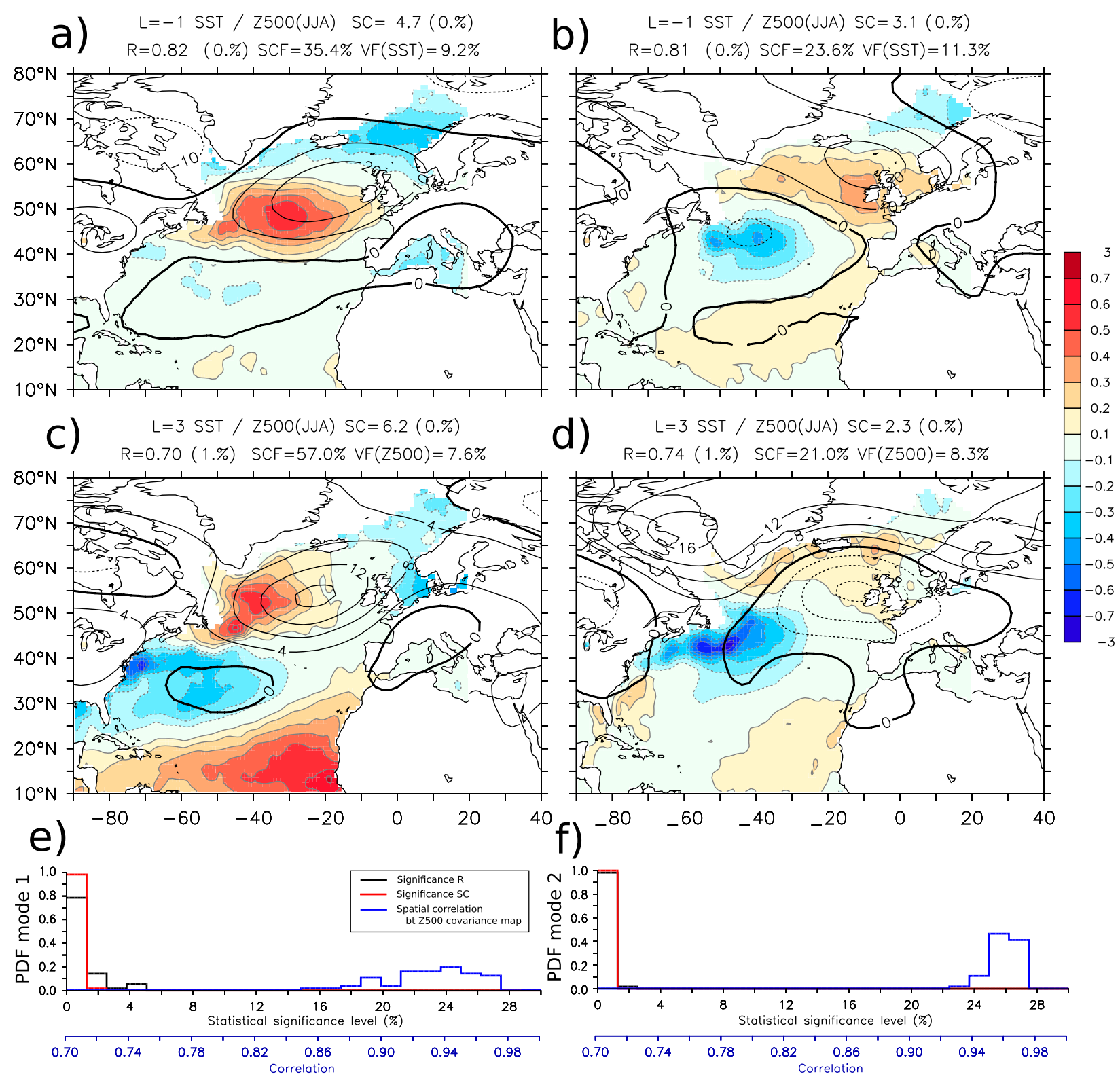

FIG. 3. (top) Covariance map of Z500 in JJA (m; contours) and SST (K; shading) for the (left) first and (right) second MCA modes. The atmosphere leads by (a),(b) 1 month or the ocean leads by (c),(d) 3 months. The SC, $R$, SC fraction (SCF), and VF of the MCA modes are indicated. (bottom) Frequency distribution of the SC (red) and $R$ significance (black) from the (e) first and (f) second MCA modes among the atmospheric ensemble members when SST leads by 3 months, and spatial correlation of the Z500 patterns with that of the $20 \mathrm{CR}$ ensemble mean (blue).

respectively. The first MCA mode is highly significant for each SST domain, but the NSC is largest for SST in $20^{\circ} \mathrm{S}-20^{\circ} \mathrm{N}$ (see Table 1 ). The MCA patterns are similar and the Z500 (SST) MCA time series have a correlation of 0.92 (0.87) between the full domain MCA and that using equatorial SST. It suggests that the SSTs in the tropical North Atlantic are likely to substantially contribute to the atmospheric response for mode 1 , as indicated by Czaja and Frankignoul (2002).
The dynamics of the atmospheric response for mode 1 was investigated using lagged regression onto the MCA SST time series of the velocity potential in JJA, simultaneous with the atmospheric response pattern, which provides information on tropical forcing (Sardeshmukh and Hoskins 1988). A similar regression is calculated for the wave activity flux from Takaya and Nakamura (2001), which is based on the conservation of pseudo momentum and provides information on where stationary Rossby 
TABLE 1. NSC and $R$ for some selected significant MCA SST-Z500 modes when the ocean leads the atmosphere (months), using SST in the North Atlantic $\left(10^{\circ}-80^{\circ} \mathrm{N}\right)$, the extratropical North Atlantic $\left(30^{\circ}-80^{\circ} \mathrm{N}\right)$, or the equatorial Atlantic $\left(20^{\circ} \mathrm{S}-20^{\circ} \mathrm{N}\right)$. For MCA using the North Atlantic $\left(10^{\circ}-80^{\circ} \mathrm{N}\right) \mathrm{SST}$, the cross-validated correlation $R_{\mathrm{CV}}$ is also indicated. For NCS and $R$, boldface numbers have associated significance level below $5 \%$.

\begin{tabular}{|c|c|c|c|c|c|c|c|}
\hline & \multicolumn{3}{|c|}{ North Atlantic $\left(10^{\circ}-80^{\circ} \mathrm{N}\right)$} & \multicolumn{2}{|c|}{$\begin{array}{l}\text { Extratropical North } \\
\text { Atlantic }\left(30^{\circ}-80^{\circ} \mathrm{N}\right)\end{array}$} & \multicolumn{2}{|c|}{$\begin{array}{c}\text { Equatorial Atlantic } \\
\left(20^{\circ} \mathrm{S}-20^{\circ} \mathrm{N}\right)\end{array}$} \\
\hline & NSC (\%) & $R$ & $R_{\mathrm{CV}}$ & NSC (\%) & $R$ & NSC (\%) & $R$ \\
\hline JJA lag $=3$ months $($ mode 1$)$ & 16.3 & 0.70 & 0.53 & 13.7 & 0.70 & 19.4 & 0.6 \\
\hline JJA lag = 3 months (mode 2) & 9.9 & 0.74 & 0.65 & 10.4 & 0.70 & 6.1 & 0.5 \\
\hline NDJ lag $=3$ months $($ mode 1$)$ & 14.5 & 0.65 & 0.38 & 14.0 & 0.65 & 13.7 & 0.6 \\
\hline NDJ lag $=8$ months $($ mode 1$)$ & 13.7 & 0.57 & 0.32 & 12.2 & 0.60 & 12.8 & 0.46 \\
\hline
\end{tabular}

wave packets are emitted and absorbed, and for the maximum Eady growth rate at $850 \mathrm{hPa} \sigma_{\mathrm{BI}}$, which is calculated as in Hoskins and Valdes (1990),

$$
\sigma_{\mathrm{BI}}=0.31 \frac{f}{N}\left|\frac{\partial \mathbf{U}}{\partial z}\right|
$$

where $f$ is the Coriolis parameter; $N$ is the Brunt-Väisälä frequency; $\mathbf{U}$ is the horizontal wind speed; and $z$ is the vertical height, which shows where midlatitude weather systems originate. Consistent with a tropical influence, a large decrease (increase) of the velocity potential anomaly is located over the tropical North Atlantic (Pacific) in Fig. 5a, indicating large-scale ascending motions over the warm SST in the tropical Atlantic that may act as a large Rossby wave source. The wave activity flux cannot be used to diagnose wave propagation across the tropics where the climatological zonal wind is weak or easterly (Takaya and Nakamura 2001). However, the wave activity flux at $500 \mathrm{hPa}$ reveals that

\section{a) SST (MJJ) Z500 (JJA) regression MCA-SST-JJA}

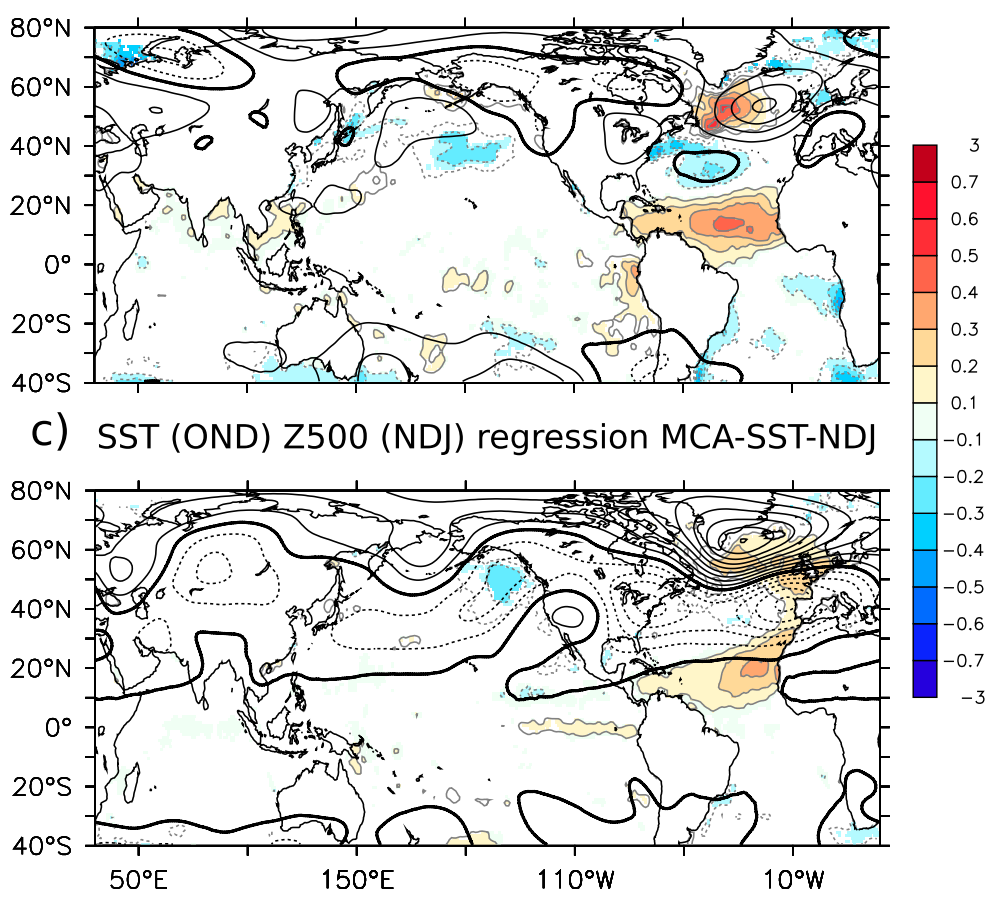

b)

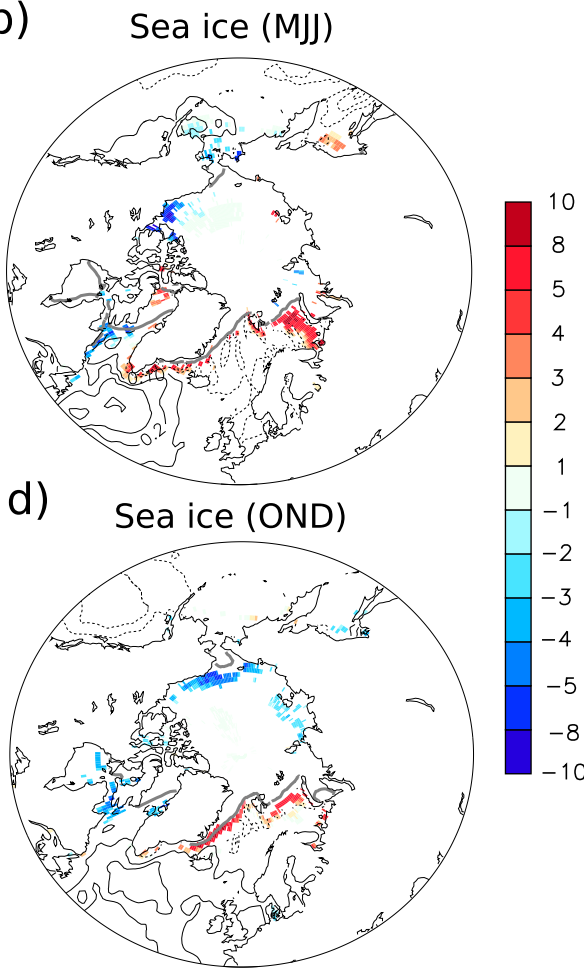

FIG. 4. Regression of (left) SST (K; color shades when 5\% significant and gray contours) and Z500 (m; black contours; contour interval of $4 \mathrm{~m}$ ) and (right) sea ice fraction (\%; color shades when 5\% significant), onto the normalized MCA SST time series for SST and sea ice leading by 1 month and Z500 in phase with the atmospheric response detected in the MCA in (top) JJA and (bottom) NDJ. (b),(d) The corresponding SST regression $(\mathrm{K})$ is indicated with black contours (contour interval of $0.1 \mathrm{~K}$; zero line omitted), and the climatological sea ice edge (sea ice cover of $50 \%$ ) is given by the thick gray line. 


\section{a) Velocity potential 200-hPa}

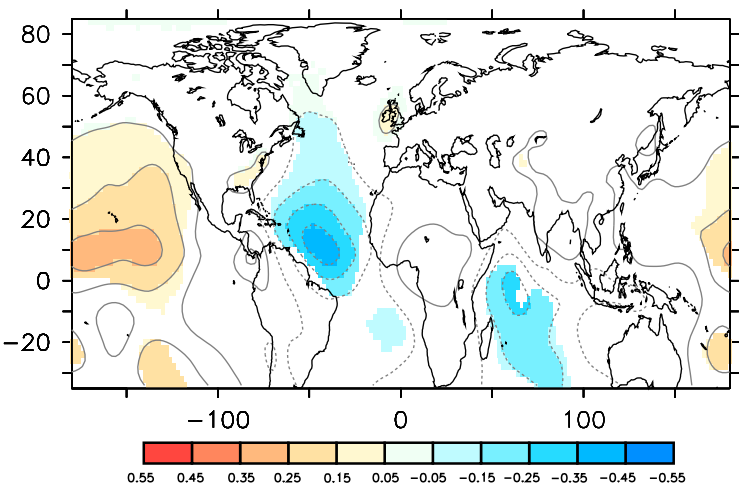

c) Eady Growth rate $850-\mathrm{hPa}$

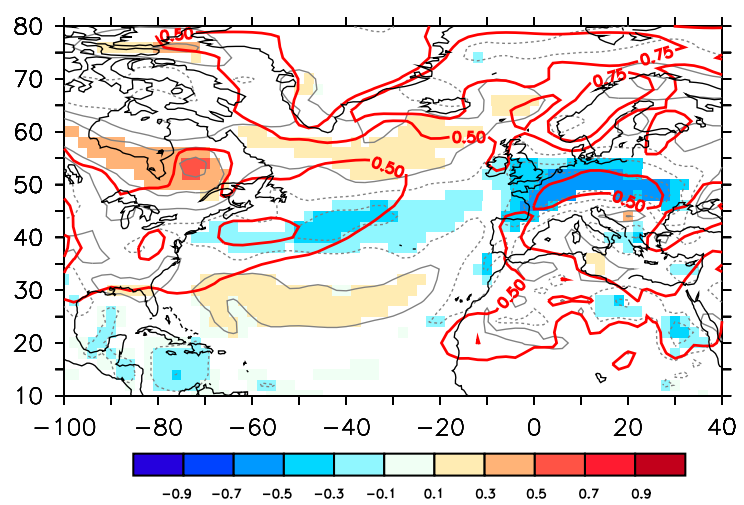

b) Wave Activity Flux

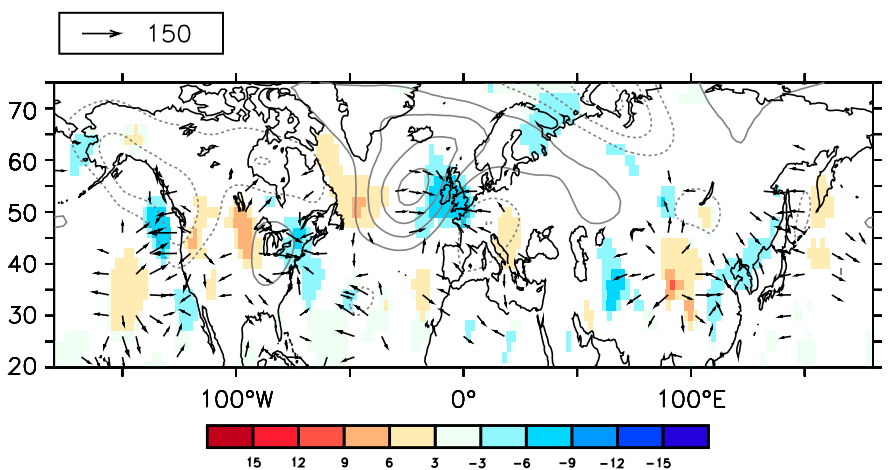

d) Zonal-mean Geopotential Height

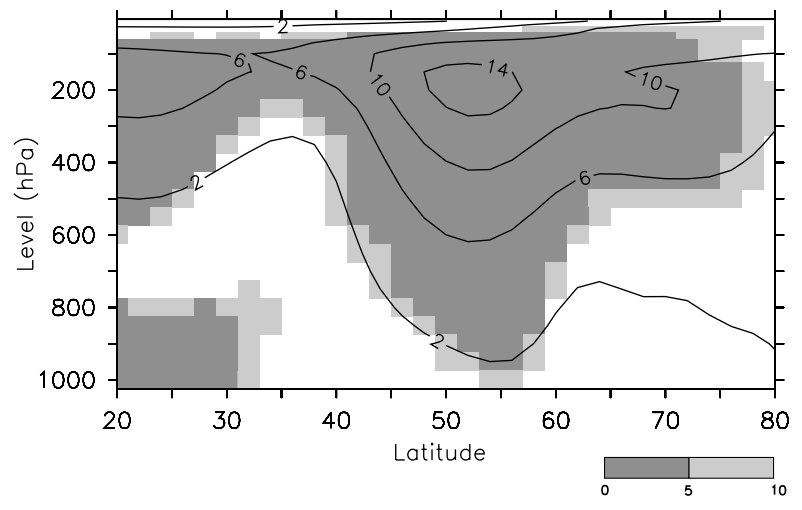

FIG. 5. (a) Velocity potential at $200 \mathrm{hPa}\left(10^{-6} \mathrm{~s}^{-1}\right)$, (b) wave activity flux, (c) Eady growth rate $\left(10^{-1}\right.$ day $\left.^{-1}\right)$, and (d) zonal-mean geopotential height $(\mathrm{m})$ over the Atlantic sector $\left(100^{\circ} \mathrm{W}-40^{\circ} \mathrm{E}\right)$ in JJA regressed onto the MCA SST time series of the first mode, when the SST leads the atmosphere by 3 months. In (b), the vectors indicate the horizontal component of the wave activity flux at $300 \mathrm{hPa}\left(\mathrm{m}^{2} \mathrm{~s}^{-2}\right.$; scaling) exceeding $35 \mathrm{~m}^{2} \mathrm{~s}^{-2}$ in strength, colors indicate the vertical component of the wave activity flux at $500 \mathrm{hPa}\left(10^{-2} \mathrm{~m}^{2} \mathrm{~s}^{-2}\right)$, and contours indicate the zonal deviations of Z500 (contour interval of $3 \mathrm{~m}$; zero line omitted). The red contours in (c) indicate the climatological mean of the Eady growth rate $\left(\mathrm{day}^{-1}\right)$. In (a)-(c), the colors are masked if the significance exceeds $5 \%, 10 \%$, and $5 \%$, respectively. In (d), gray shades indicate the significance $(\%)$.

upward wave activity propagation occurs over the North American continent and off Newfoundland and Greenland (Fig. 5b, colors). In the upper troposphere, the wave activity flux propagates away from the western subpolar North Atlantic, across the anomalous high east of the British Isles, where the wave activity converges (Fig. 5b, vectors). The stationary Rossby wave emanation from the western subpolar region suggests that the extratropical SST also has an influence. The zonal deviations of the Z500 anomalies have a global wavenumber 4 pattern, with circulation anomalies over Eurasia and the North Pacific (Fig. 5b, gray contours), so that the circulation anomalies also have a global teleconnection pattern, as found by Lee and Hsu (2013). The Eady growth rate (Fig. 5c) decreases over the central North Atlantic, and increases both north and south of its climatological maximum. The storm track therefore moves northward, which corresponds to the changes associated with the EAP (Lau 1988). Note that the increased baroclinicity between Newfoundland, Greenland, and Iceland is consistent with the upward wave activity flux at this location. The geopotential height anomalies are baroclinic, except between $40^{\circ}$ and $60^{\circ} \mathrm{N}$, where the structure is equivalent barotropic, suggesting important eddy-mean flow interactions (Fig. 5d). These diagnostics are consistent with an atmospheric response to both tropical and extratropical SST forcing.

The same analysis was performed for mode 2 , but it is only briefly summarized, as its SC fraction $(21 \%)$ is smaller. Mode 2 is only significant when extratropical SSTs are included in the MCA (Table 1), suggesting a larger active role for the extratropical Atlantic. Moreover, the global SST anomalies and the dynamical diagnostics also suggest a larger influence from the North Atlantic (not shown) compared to mode 1. 


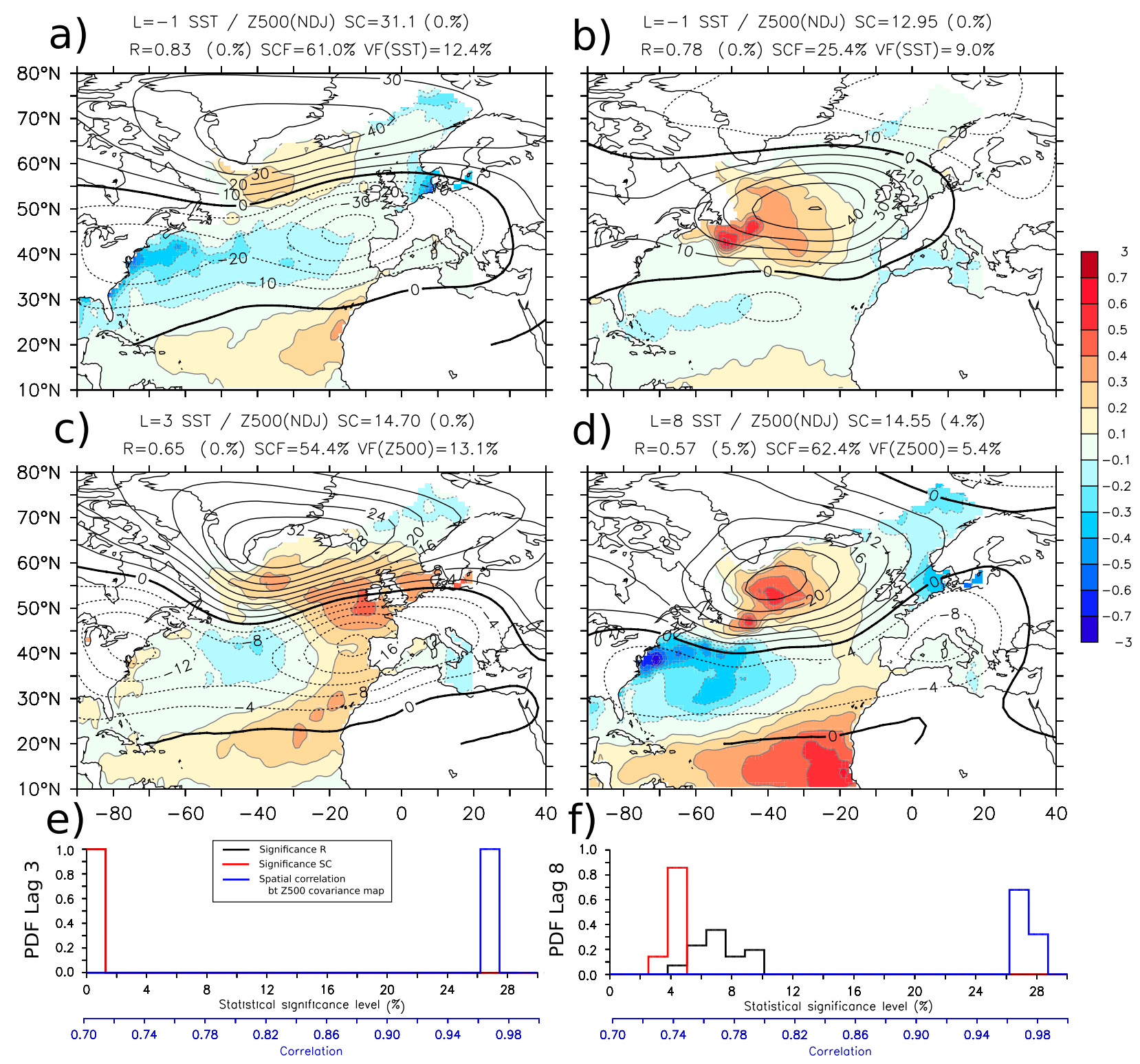

FIG. 6. Covariance map of Z500 (m; contour) and SST (K; shading): (a) first and (b) second MCA mode when the NDJ atmosphere leads SST by 1 month and first MCA mode when the NDJ atmosphere lags by (c) 3 and (d) 8 months. The SC, $R$, SCF, and VF of the MCA modes are indicated. Frequency distribution of the SC (red) and $R$ (black) significance from the first MCA mode among the ensemble members when SST leads by (e) 3 and (f) 8 months and spatial correlation of the Z500 patterns with that of the 20CR ensemble mean (blue).

\section{c. Late fall-early winter SST influence}

A significant SST influence onto the atmosphere in October-December (OND), November-January (NDJ), and to a lesser extent December-February (DJF) is suggested by the first MCA mode in Fig. 2, while mode 2 (not shown) is not significant. As the results are similar, only NDJ is presented for conciseness. When the NDJ atmosphere leads the SST by 1 month, the first MCA mode reflects the NAO (shown in its negative phase) forcing of the North Atlantic SST anomaly tripole (Fig. 6a). The second mode (Fig. 6b) illustrates the influence of the EAP onto the SSTs in a broad region centered along the Gulf Stream and the North Atlantic Current (Cayan 1992).

The first MCA mode is also significant when SST leads. It is most significant when SST leads by 3 months and remains $10 \%$ significant for a lag of up to 9 months, with a weaker significance around 5 months (Fig. 3), presumably because it corresponds to SST in JJA when 
a) Velocity potential $200-\mathrm{hPa}$

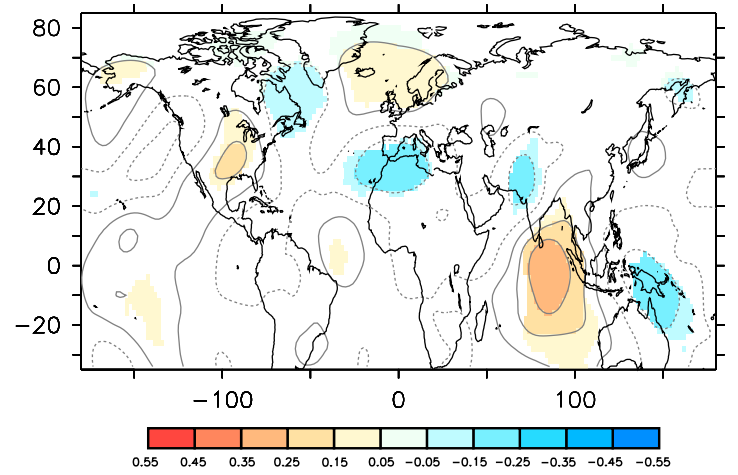

c) Eady Growth rate $850-\mathrm{hPa}$

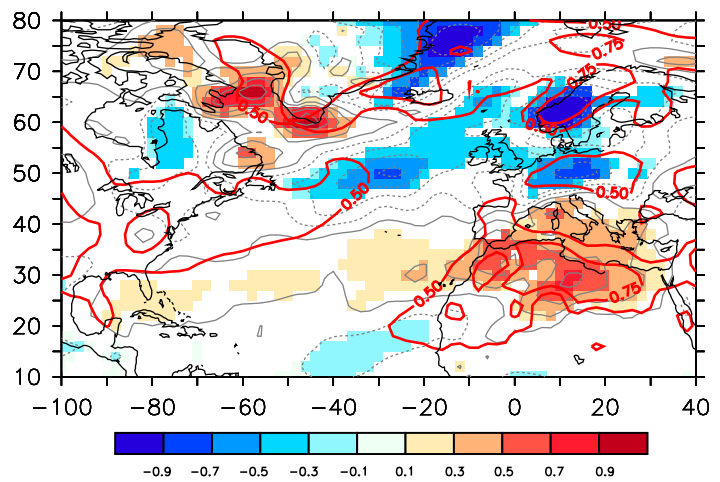

b) Wave Activity Flux

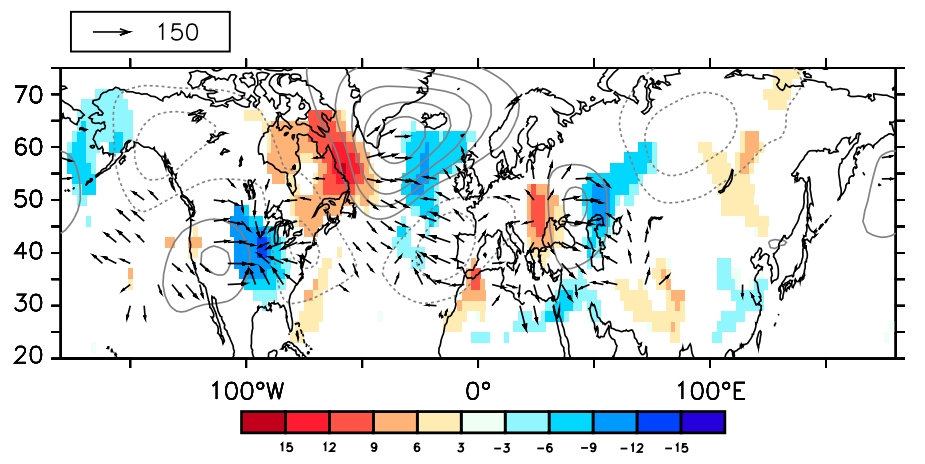

d) Zonal-mean Geopotential Height

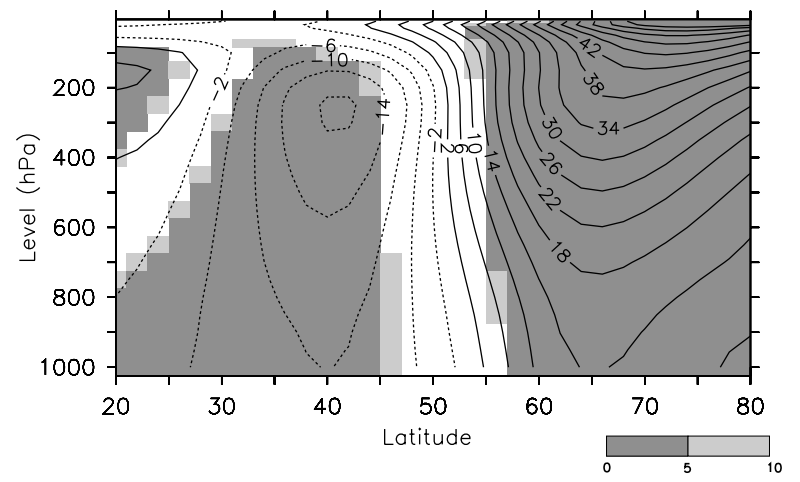

FIG. 7. As in Fig. 5, but for the atmospheric response in NDJ, using $5 \mathrm{~m}$ as contour intervals for the Z500 deviations from the zonal mean (contours) in (b).

the mixed layer is shallow, and the SST variability is large; thus, the signal-to-noise ratio of the SST forcing pattern is smaller. The MCA patterns change a little with the lag, as illustrated for lag 3 (Fig. 6c) and lag 8 (Fig. 6d), but they show the influence of the NAH SST anomaly onto the fall and early winter NAO, albeit southward shifted, with anomalous warming in the subpolar regions and the eastern subtropics leading a negative NAO-like pattern, as discussed previously (Czaja and Frankignoul 1999, 2002; Peng et al. 2002, 2003; Drévillon et al. 2001; Frankignoul et al. 2013). It suggests a small but significant potential predictability of the NAO in NDJ, because the cross-validated correlation is about 0.4 (Table 1 ) and the SST explains about $13 \%$ of the Z500 variance. In fact, there is already some small predictive NAO skill from SST as early as JFM, as seen from the SC and $R$ significance at lag 8 (Fig. 6d), which suggests an influence of SST changes on longer time scales, although the NAH SST pattern is in part driven by stochastic atmospheric forcing (Czaja and Frankignoul 2002; Gastineau et al. 2013). Note that, despite the slight southward NAO shift in Fig. 6c, the MCA Z500 time series is highly correlated $(R=0.94)$ with the NAO defined as the first EOF of Z500 in NDJ. The regression of OND SST anomalies onto the MCA SST time series for lag 3, leading to the atmospheric response 1 month later in NDJ, is shown in Fig. 4b. The SST anomalies have strongly persisted in the subpolar North Atlantic and, to a lesser extent, in the subtropical eastern Atlantic, while the SST anomalies are smaller elsewhere. Hence, the oceanic influence mainly comes from the North Atlantic. When the SST is only considered in limited domains, only the MCA including the SST north of $30^{\circ} \mathrm{N}$ gives a significant mode at lag $\geq 3$ (see Table 1), with similar patterns, suggesting that the extratropical North Atlantic SST anomalies play the driving role, as found by Czaja and Frankignoul (2002) and Frankignoul and Kestenare (2005).

To illustrate how the North Atlantic SSTs drive the NAO-like response, we regress as before a number of atmospheric fields in NDJ on the SST MCA time series obtained at lag 3, so that they are simultaneous with the Z500 response in Fig. 6c. The velocity potential anomalies show weak ascending motions over the Labrador Sea and the eastern subtropical North Atlantic, but strong subsidence over the eastern Indian Ocean (Fig. 7a). In addition, the wave activity flux shows strong upward wave propagation over the Labrador Sea (Fig. 7b). These waves propagate northward and eastward, and then 
downward over the eastern North Atlantic and the Nordic seas. The Eady growth rate is increased over the southern tip of Greenland and along its eastern coast but decreased east of Newfoundland (Fig. 7c). The decrease in baroclinicity is extended downstream along the North Atlantic Current and the Scandinavian coast, corresponding to a southward shift of the baroclinicity and the storm track. This shift is mainly due to the zonal wind shear, consistent with the smaller meridional SST gradient at $50^{\circ} \mathrm{N}$, over the North Atlantic Current. The geopotential height anomalies are equivalent barotropic (Fig. 7d), consistent with an amplification due to eddy feedback. Hence, all the diagnostics are consistent with a local driving of the NAO-like response by warmer conditions in the Newfoundland and Labrador Sea region.

To explore the influence of other boundary forcing, the anomalies in Arctic sea ice concentration and Eurasian snow cover concomitant with the NAH SST anomaly were considered. Sea ice cover may also play a role, as significant sea ice concentration anomalies are found in the Greenland Sea, where an advance of the sea ice edge reflects the ocean cooling (Fig. 4d). The sea ice fraction is also reduced over the Canadian Archipelago and the northern Labrador Sea. On the other hand, there were no significant Eurasian snow cover anomalies in the 20CR (not shown).

\section{Atmospheric response to the decadal SST variability}

\section{a. Significance and seasonality}

To investigate the ocean-atmosphere interactions at the decadal scale, we work with low-pass-filtered fields, which should emphasize the atmospheric response to slowly varying SSTs by strongly reducing the amplitude of the intrinsic short-time-scale variability of the atmosphere, thereby enhancing the signal-to-noise ratio. The low-pass filtering will not mask the driving influence of the atmosphere, for instance by NAO fluctuations, because atmospheric forcing acts as a white noise, so that its phase relation with the SST anomaly response should not be distorted by the filtering (Hasselmann 1976; Frankignoul and Hasselmann 1977; Frankignoul 1979). Of course, small departures from atmospheric whiteness will play an increasing role.

To emphasize the low-frequency variability and increase the signal-to-noise ratio without affecting seasonality, we apply an elementary binomial smoothing $(1 / 4-1 / 2-1 / 4)$ to all time series prior to the MCA, so that, for example, JFM at year $t\left(\mathrm{JFM}_{t}\right)$ is replaced by $1 / 4 \mathrm{JFM}_{t-1}+1 / 2 \mathrm{JFM}_{t}+1 / 4 \mathrm{JFM}_{t+1}$, and we extend the period to 1930-2010 to increase the number of degrees of freedom. Statistical significance is calculated using blocks of $5 \mathrm{yr}$ to account for the larger autocorrelation of the atmospheric time series. Because of the smoothing, modes of covariability obtained when the ocean leads by 1 or 2 yr may reflect the SST impact onto the atmosphere and/or the atmospheric forcing of the SST. Hence, only modes of covariability obtained when the ocean leads by at least $27(24+3)$ months can be unambiguously used to detect an influence of the ocean onto the atmosphere. This requires that the SST anomalies be sufficiently persistent.

Figure 8 indicates that the maximum covariability between SST and Z500 occurs at negative lag when SST follows Z500 in DJF and JFM by 1 or 2 months, which reflects the forcing of the SST anomaly tripole by the $\mathrm{NAO}$ as in Fig. 6a, albeit with a larger subpolar warming (Fig. 9a), presumably reflecting the larger mixed layer depth and SST anomaly persistence in the subpolar North Atlantic, and a larger influence of advection due to Ekman currents. There are decreasing SC maxima when SST follows by multiples of about 12 months (atmosphere leads) with similar patterns. They result from the smoothing and from SST reemergence (e.g., de Coëtlogon and Frankignoul 2003), which can be followed until lag -48 . There is also significant evidence of a weaker SST response in the fall, with a clear sign of reemergence, with patterns similar to mode 2 shown in Fig. 6b, showing the influence of the EAP. During winter, the SST response to the EAP appears as MCA mode 2.

When SST leads Z500 by more than $2 \mathrm{yr}$, there is no significant mode in OND and NDJ. However, a highly significant signal is now found in winter (DJF and JFM) for a lag of more than $4 \mathrm{yr}$, with maximum SC when the SST is taken in NDJ and DJF. For the summer atmosphere, there is only significance in both $\mathrm{SC}$ and $R$ around JJA when the ocean leads by $0-8$ months and 18 19 months. Since the SC and the significance are much smaller at negative lag when the atmosphere leads, it is tempting to attribute the mode to a weak summer atmospheric response to SST. In fact, it (noisily) reflects a summer atmospheric response that is primarily confined to the lower troposphere. For instance, there is a significant response at lag up to 32 months when using the temperature at $850 \mathrm{hPa} T_{850}$ as atmospheric variable.

\section{b. Summer AMO influence}

Figure 10a represents the patterns for the MCA between $T_{850}$ and SST when SST leads by 32 months (similar patterns are found at shorter lag). The SST pattern resembles the AMO shown in Fig. 1, and the MCA SST time series has the same multidecadal fluctuations 


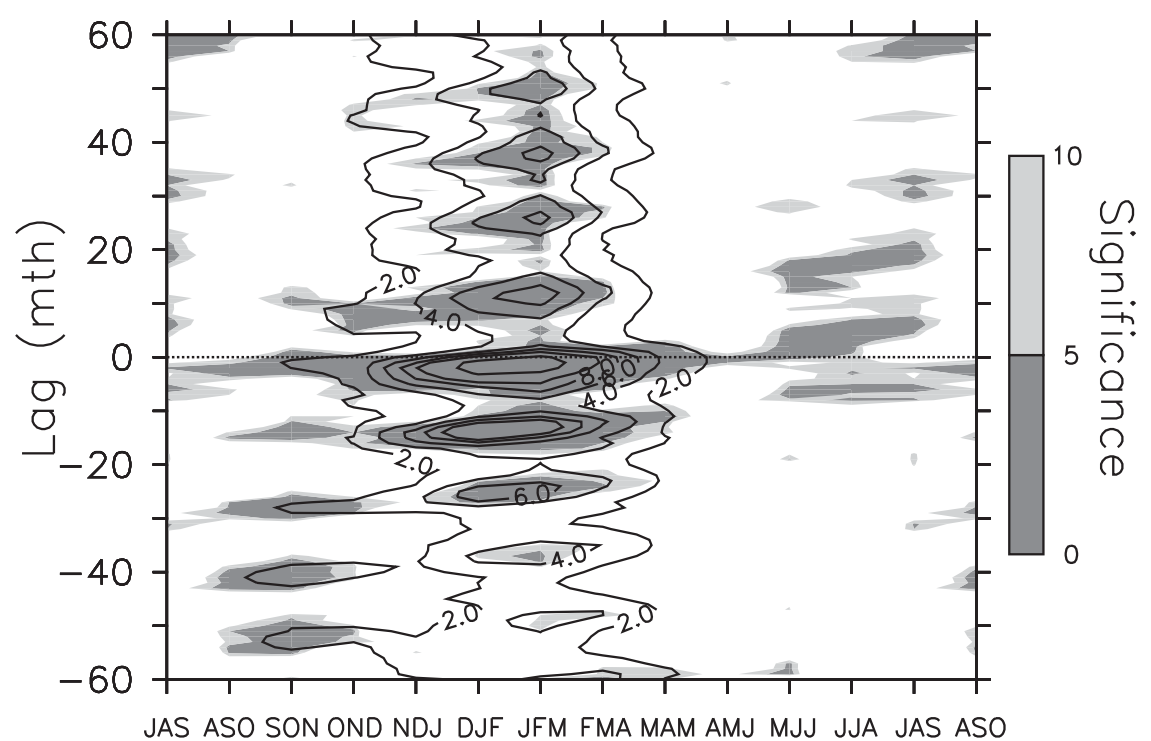

FIG. 8. SC $\left(10^{2} \mathrm{hPa}^{2} \mathrm{~K}^{2}\right)$ of the first MCA mode between $\mathrm{Z} 500$ and SST after applying a lowpass filter $(1 / 4-1 / 2-1 / 4)$, using the whole time period $1930-2010$. The lag (months) is negative (positive) when atmosphere leads (lags).

(Fig. 1b, red line), suggesting that the summer mode describes the atmospheric response to the AMO. Note, however, that there are also prominent decadal fluctuations, suggesting that the AMO also significantly varies at the decadal time scale. However, the filtering (10- or 15-yr cutoff) generally used to calculate the AMO masks these fluctuations. The lower-tropospheric temperature displays a warming over northeastern Europe and eastern North America, while the Mediterranean region experiences cooling, as shown by Sutton and Hodson (2005). The associated SLP anomalies (Fig. 10b) are mostly negative, except for a strong anticyclone over eastern Europe, which resembles that occurring in blocking situations (Matsueda 2011). The warming is largest below $700 \mathrm{hPa}$ and baroclinic in the tropics and subtropics (not shown). The global regression of the JJA $T_{850}$ anomalies onto the MCA SST index from the SST $-T_{850}$ analysis, lagged by 32 months to be in phase with the atmospheric response in Fig. 10a, shows that there is also a strong warming over Siberia and a very weak one over the tropical oceans (Fig. 11a). The precipitation changes are more uncertain and noisy, especially over land, but suggest a decrease of precipitation over northeastern Brazil, western Russia, and to a lesser extent the U.S. Great Plains and more precipitation over western Africa and southern Europe (Fig. 11b), sharing some similarities with other studies (Sutton and Hodson 2005; Nigam et al. 2011; Ting et al. 2014). The precipitation is also modified in the Pacific Ocean, where the intertropical convergence zone shifts southward.
Why is the summer mode seen at the seasonal scale not found at the decadal scale? A likely explanation is that the persistence of the SST driving patterns at the seasonal scale is limited, preventing detection at the large lag required to detect the response to decadal SST fluctuations. This is shown in Fig. 12 (red line) by the autocorrelation of the MJJ SST pattern illustrated in Fig. 3c, which loses significance after less than 20 months.

\section{c. Winter AMO influence}

The covariance maps of the MCA between low-passfiltered SST and Z500 in JFM are shown in Fig. 9b when SST leads by 38 months, as the MCA mode 1 has a maximum SC, and the atmospheric pattern can be unambiguously interpreted as an atmospheric response. It corresponds to covariability between the SST in NDJ and the JFM Z500 3 yr later, but the patterns are unchanged when using different lags. An NAH-like SST anomaly, albeit with a much larger subpolar maximum, precedes the appearance of a dipolar geopotential height anomaly that resembles a negative NAO, consistent with the 0.97 correlation between the MCA Z500 time series and the NAO. Although the SST pattern is rather similar to that in Figs. $6 \mathrm{c}$ and $6 \mathrm{~d}$, the much larger amplitude in the subpolar Atlantic makes it resemble the AMO (Fig. 1). The MCA SST time series associated fluctuates at the low frequency like the AMO (Fig. 1, thin blue line), although there are also some prominent decadal fluctuations at periods of about $10 \mathrm{yr}$. This is further supported by the correlation of the MCA SST time series with the (similarly) weakly low-pass-filtered 

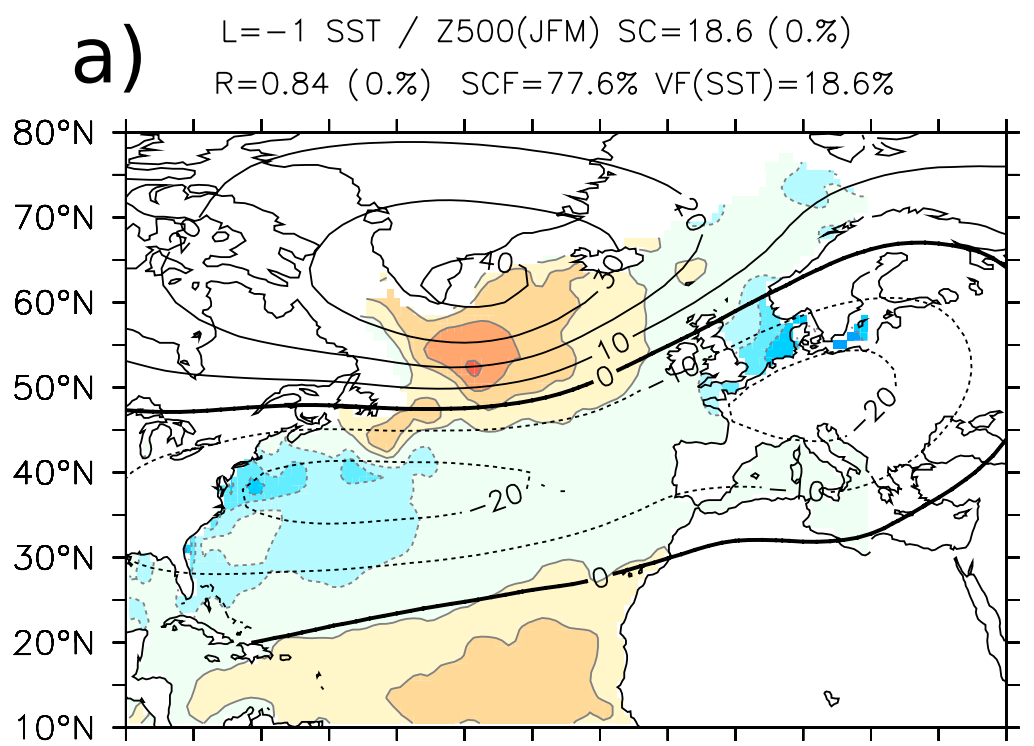

b) $\begin{aligned} & \mathrm{L}=38 \mathrm{SST} / \mathrm{Z} 500(\mathrm{JFM}) \mathrm{SC}=8.90(0 . \%) \\ & \mathrm{R}=0.59(4 . \%) \quad \mathrm{SCF}=80.8 \% \mathrm{VF}(\mathrm{Z} 500)=12.7 \%\end{aligned}$
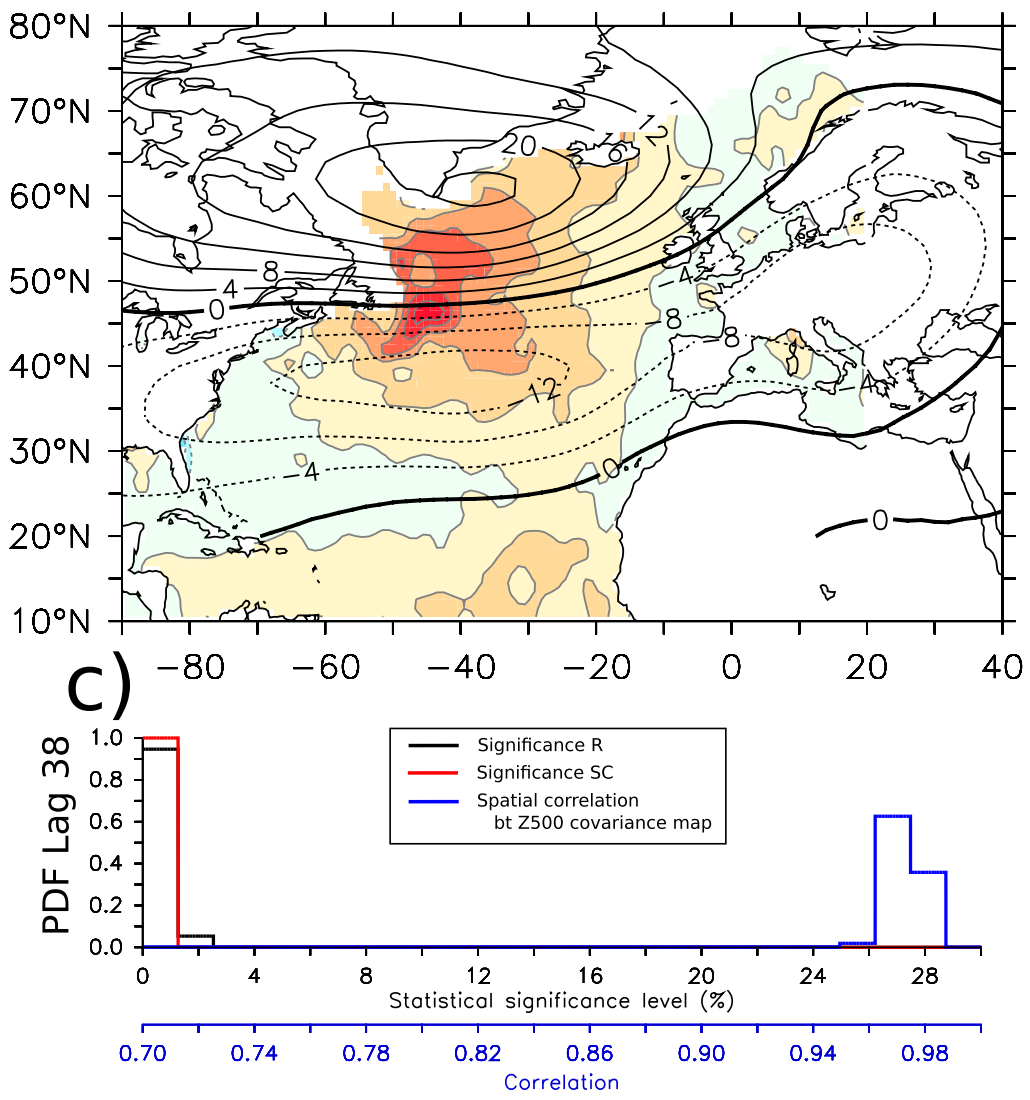

FIG. 9. Covariance map of low-pass-filtered Z500 (m; contour) and SST (K; shading) for mode 1 when the JFM atmosphere (a) leads SST by 1 month and (b) lags SST by 38 months. The SC, $R$, associated significance, SCF, and VF of the MCA modes are indicated at the top of each map. (c) Frequency distribution of the SC (red) and $R$ (black) significance from the first MCA mode among the atmospheric ensemble members for lag 38 and spatial correlation of the Z500 patterns with that of the 20CR ensemble mean (blue). 
a) $\quad \mathrm{L}=32 \mathrm{SST} / \mathrm{T} 850(\mathrm{JJA}) \mathrm{SC}=19.0(1 . \%)$ $\mathrm{R}=0.71(2 . \%) \quad \mathrm{SCF}=51.8 \% \mathrm{VF}(\mathrm{T} 850)=7.2 \%$

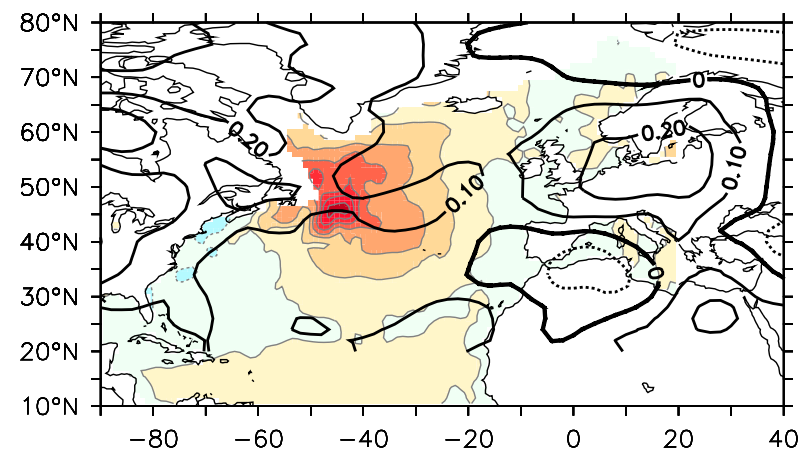

b) PRMSL (JJA) regression

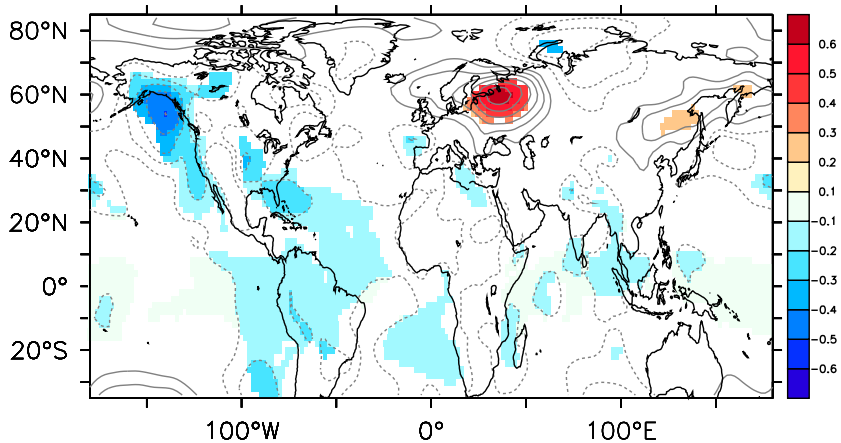

FIG. 10. (a) Covariance map of low-pass-filtered SST (K; colors at $0.1-\mathrm{K}$ interval) and $T_{850}(\mathrm{~K}$; contours) for the MCA mode 1 when the JJA atmosphere lags SST by 32 months. The SC, $R$, their significance, SCF, and VF are indicated on top. (b) SLP regression (hPa) onto the MCA SST time series corresponding to the pattern shown in (a). Color shades indicate $5 \%$ significance.

time series obtained by projecting the SST onto the AMO pattern (referred to as MCA-LPF-SST), which is maximum at zero lag, demonstrating their close link (Fig. 13). Interestingly, the similarly low-pass-filtered NAO time series in JFM is also significantly correlated with the MCA-LPF-SST when the SST leads by $0-5 \mathrm{yr}$, with maximum correlation at lag 3 , but not when the NAO leads. This again strongly suggests that the AMO influences the winter NAO. The negative NAO phase that follows the AMO can be detected from SST leading by up to $4 \mathrm{yr}$, reflecting the large AMO persistence. The AMO influence on the NAO is robust, as the JFM MCA mode 1 at lag 38 is $5 \%$ significant in all the 56 members of the 20CR ensemble, with the same spatial pattern (Fig. 9d).

To study the links between North Atlantic atmospheric circulation and SST, an MCA was repeated using SST north of $30^{\circ} \mathrm{N}$ or between $20^{\circ} \mathrm{S}$ and $20^{\circ} \mathrm{N}$ (Table 2). The

\section{a) T 850-hPa (MCA in JJA)}

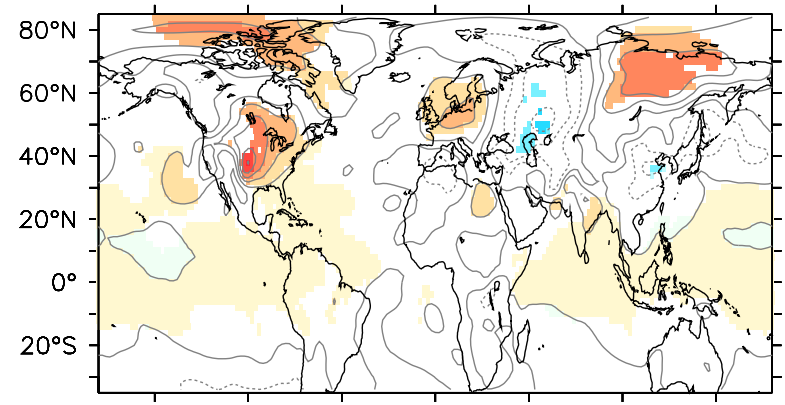

c) T 850-hPa (MCA in JFM)

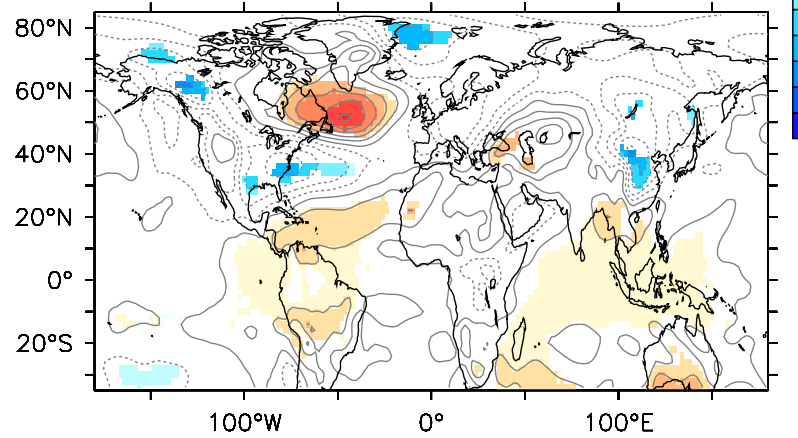

b) Rainfall (MCA in JJA)

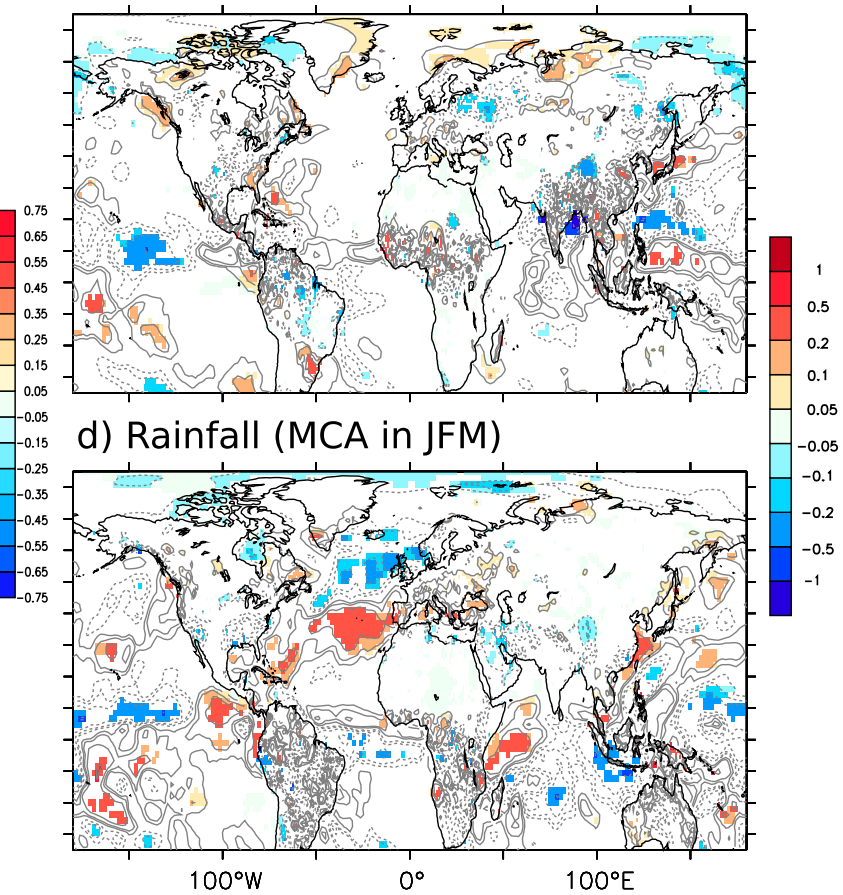

FIG. 11. Climate impact of the SST low-frequency variability: atmospheric temperature at $850 \mathrm{hPa}(\mathrm{K})$ in (a) JJA and (c) JFM and rainfall $\left(\mathrm{mm} \mathrm{day}^{-1}\right)$ in (b) JJA and (d) JFM. The color shades are masked if the significance level is above $5 \%$. 
SST DJF (from MCA-JFM using low-pass filter) SST OND (from MCA-NDJ) SST MJJ (from MCA-JJA)

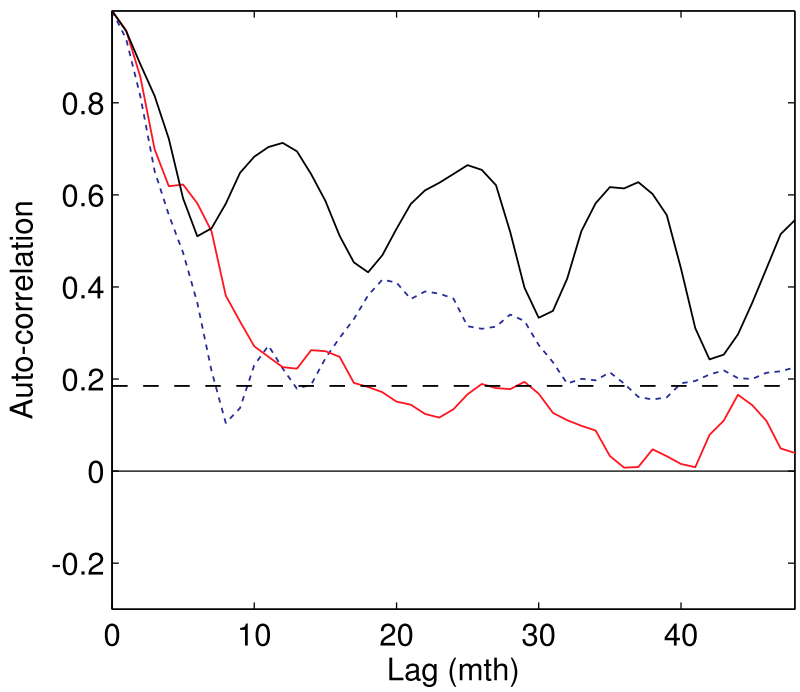

FIG. 12. Seasonal autocorrelation of the projection onto the SST anomaly preceding the NDJ (blue line), JJA (red line), and JFM (black line) atmospheric response in the MCA (shown in Figs. 4b, d and 14), starting from OND, MJJ, and DJF, respectively. Dashed lines represent the one-sided $5 \%$ significance level for zero correlation neglecting serial autocorrelation.

two MCA provide comparable results, so that the two domains cannot be distinguished in this way. We calculated the regression of the similarly filtered fields onto the MCA-LPF-SST, lagged in order to be simultaneous with (for the atmospheric fields) or 1 month before (for SST) the JFM atmospheric response shown in Fig. 9b. It reveals that the DJF SST anomalies leading to the atmospheric response 1 month later has a similar spatial pattern in the North Atlantic compared to that shown in Fig. 9, although its amplitude is reduced (Fig. 14). The wave activity flux anomalies (Fig. 15b) are mainly upward over northern Canada and downward over the eastern subpolar Atlantic. There is some weaker upward wave activity flux over the northern subtropical Atlantic Ocean, around $35^{\circ} \mathrm{N}, 20^{\circ} \mathrm{W}$, off the coast of Spain and Morocco, while the wave activity propagates northward over the eastern North Atlantic and westward over the subpolar region. The Eady growth rate increases over the subtropical North Atlantic and the southern Labrador Sea (Fig. 15e), while it decreases downstream of the Gulf Stream and the North Atlantic Current, where the climatological Eady growth rate is largest (red contours in Fig. 15e). The velocity potential at $200 \mathrm{hPa}$ (Fig. 15a) only shows weak ascending motion over the subtropical North Atlantic and the Mediterranean Sea. The eastern tropical

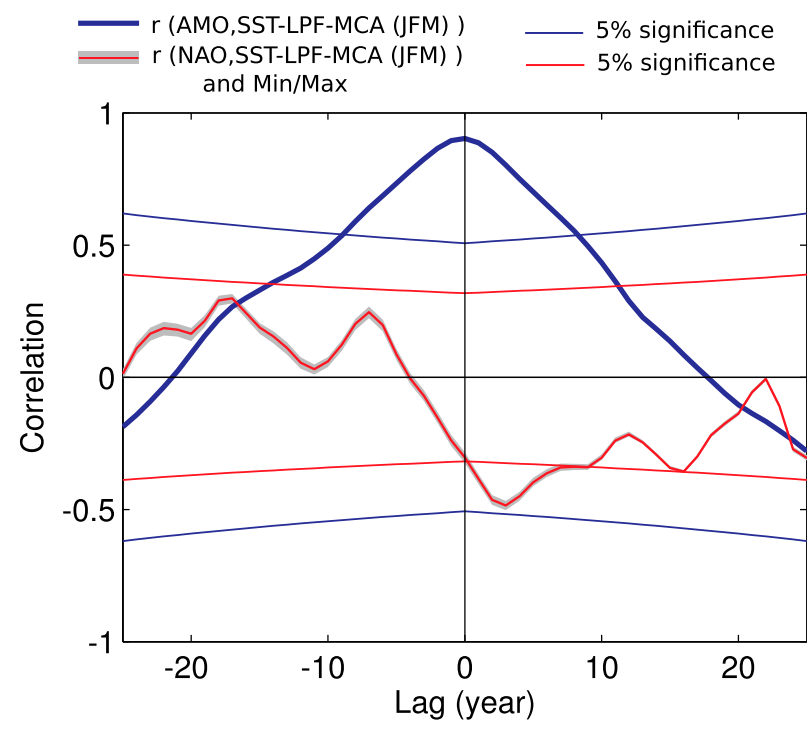

FIG. 13. Correlation between MCA-LPF-SST (JFM) and AMO (blue line) and MCA-LPF-SST (JFM) and NAO (red line). The lag is positive when MCA-LPF-SST leads. The gray shades indicate the spread ( $\min$ and $\max$ ) of the correlation between MCA-LPFSST and NAO among the 20CR ensemble members.

Pacific also shows ascending motion, which indicates a possible tropical Rossby wave source over that region, while subsiding motion are located over the western Pacific, the eastern Indian Ocean, and South America. The zonal wind at $250 \mathrm{hPa}$ (Fig. 15c) shows that the jet stream shifts southward over the Atlantic Ocean, consistent with a negative NAO. The response is equivalent barotropic in the troposphere (Fig. 15d). The polar vortex is not involved into the dynamics, as confirmed by the regression of the averaged geopotential height over the North Atlantic sector $\left(55^{\circ}-90^{\circ} \mathrm{N}, 100^{\circ} \mathrm{W}-40^{\circ} \mathrm{E}\right)$ from ASO to MAM onto the MCA-LPF-SST. We found no significant Eurasian snow cover (not shown) and negligible sea ice concentration anomalies (Fig. 14b) in 20CR preceding and simultaneous with the atmospheric response.

TABLE 2. NSC and $R$ for some selected significant MCA SSTZ500 modes, after using a low-pass filter, when the ocean leads the atmosphere by more than $3 \mathrm{yr}$, using only SST in the extratropical North Atlantic $\left(30^{\circ}-80^{\circ} \mathrm{N}\right)$ or in the equatorial Atlantic $\left(20^{\circ} \mathrm{S}-20^{\circ} \mathrm{N}\right)$. Boldface numbers have associated significance level below $5 \%$.

\begin{tabular}{|c|c|c|c|c|}
\hline & \multicolumn{2}{|c|}{$\begin{array}{l}\text { Extratropical } \\
\text { North Atlantic } \\
\left(30^{\circ}-80^{\circ} \mathrm{N}\right)\end{array}$} & \multicolumn{2}{|c|}{$\begin{array}{c}\text { Equatorial } \\
\text { Atlantic } \\
\left(20^{\circ} \mathrm{S}-20^{\circ} \mathrm{N}\right)\end{array}$} \\
\hline & NSC (\%) & $R$ & NSC (\%) & $R$ \\
\hline JFM lag $=38$ months & 10.5 & 0.58 & 9.1 & 0.51 \\
\hline JFM lag $=48$ months & 8.8 & 0.56 & 9.2 & 0.49 \\
\hline
\end{tabular}


a)

$$
\text { SST (DJF) and Z500 (JFM) regression }
$$
onto MCA-LPF-SST

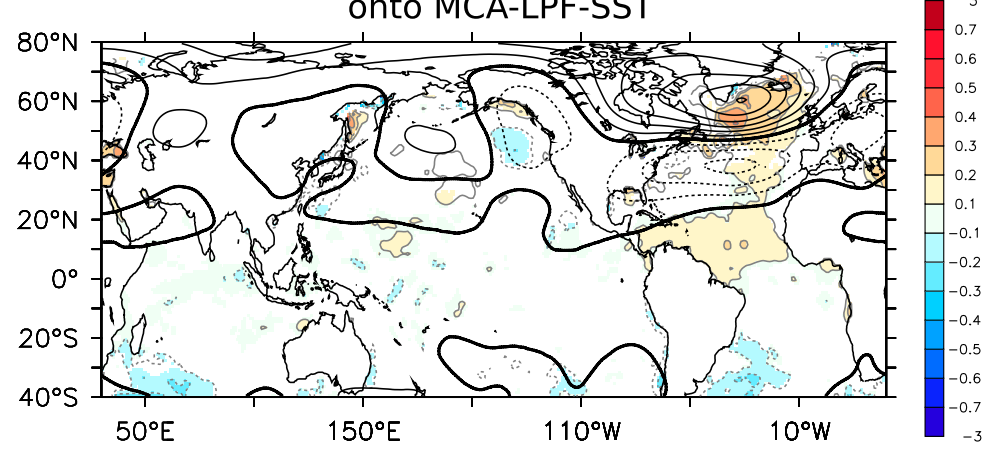

b) Sea ice (DJF)

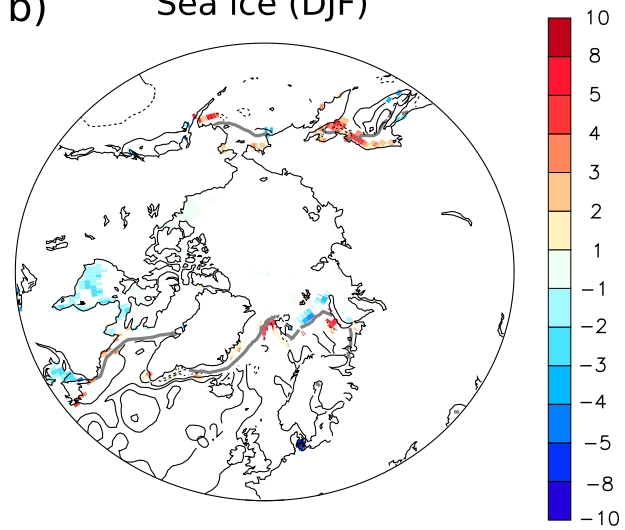

FIG. 14. Regression of (a) SST (K; color shades when $5 \%$ significant and gray contours) and Z500 (m; black contours; contour interval of $4 \mathrm{~m}$ ) and (b) sea ice fraction (\%; color shades when 5\% significant), onto the normalized MCA-LPF-SST for SST and sea ice leading by 1 month and Z500 in phase with the atmospheric response detected in the MCA in JFM. In (b), the corresponding SST regression (K) is indicated with black contours (contour interval $0.1 \mathrm{~K}$; zero line omitted), and the climatological sea ice edge (sea ice cover of $50 \%$ ) is given by the thick gray line.

There are some discrepancies in the cold season atmospheric response found in the seasonal MCA (in Fig. 6) and that using low-pass-filtered data (in Fig. 9). First, the SST anomaly in Fig. 9b is larger in the subpolar domain and weaker in the tropics and subtropics and the Z500 pattern is more NAO like. More importantly, the response to SST anomalies is significant in late fall and early winter in the seasonal case but in winter when using a low-pass filter, about 2 months later. This may be due in part to different SST anomaly persistence, as illustrated in Fig. 12 by the seasonal autocorrelation of the corresponding SST time series. These time series are obtained by projecting the MCA SST patterns onto the SST anomaly field. The autocorrelation of the DJF SST anomaly that precedes the JFM response in Fig. 9b (Fig. 12, black line) decreases to a minimum at lag 6, which corresponds to spring (JJA) when the seasonal mixed layer shrinks, and then increases again as the mixed layer deepens and the anomalies insolated below the seasonal thermocline reemerge, reaching a second maximum at lag 12 in DJF and thereafter at yearly intervals (Fig. 10, black line). On the other hand, the SST anomaly in OND that precedes the NDJ response in the seasonal analysis (Fig. 6c) shows a much stronger decrease of its autocorrelation from 0 to lag 8 and less evidence of reemergence, even if a maximum is reached near lag 19. Hence, the seasonal SST based on low-passfiltered data is much more persistent in DJF than that in OND. This, as well as the reduction of the large atmospheric variability in winter by the filtering, should favor the detection of an atmospheric response at a large lag in JFM. It may also be that the strengthened subpolar anomaly in Fig. 9b favors a response later in the season.
Based on the MCA-LPF-SST index, the regressions of the $850-\mathrm{hPa}$ temperature and precipitation, in phase with the atmospheric signal, show changes broadly similar to those associated with a negative NAO (Figs. 11c,d). There is a cooling over southeastern United States and northern China and a small cooling over western Europe and the Nordic seas, albeit marginally significant (only at the $10 \%$ level), while a broad region centered over the Labrador Sea and northern Canada is anomalously warm. There is also a small warming over the tropics. Consistent with the southward shift of the storm track associated with a negative NAO, precipitation shows a dipolar anomaly with less rain over the eastern coast of the United States, the British Isles, and Scandinavia and more rain in southern Europe and the Mediterranean region, similar to Ting et al. (2014). There is also less rain over the equatorial Atlantic and Pacific and significant changes in the Southern Hemisphere.

\section{Discussion and conclusions}

After a careful removal of global warming effects and tropical teleconnections, MCA of SST and 500-hPa geopotential height using the $20 \mathrm{CR}$ were used to find atmospheric signals related to prior North Atlantic SST anomalies. Dynamical diagnostics such as Eady growth rate, wave activity flux, and velocity potential were used to discuss the possible mechanisms of the atmospheric response. During summer, an EAP-like anticyclone over the subpolar North Atlantic was found to lag an SST anomaly tripole with warm SST anomalies in the tropical North Atlantic and off Newfoundland and cold ones in the subtropical western North Atlantic. This 
a) Velocity potential $200-\mathrm{hPa}$

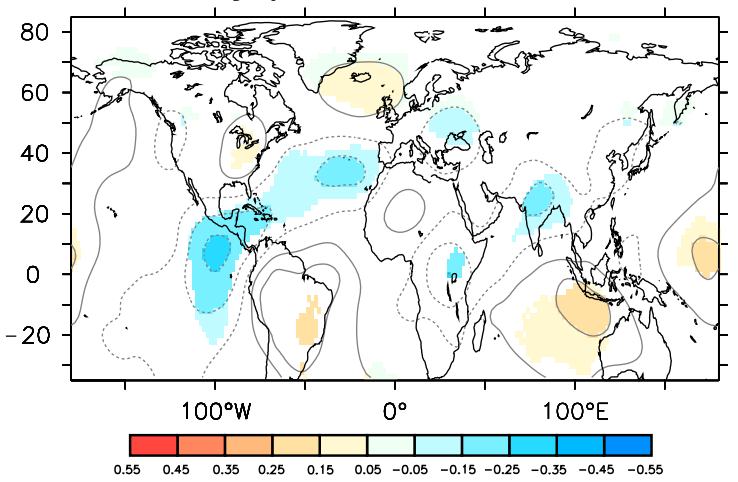

c) Zonal wind $250-\mathrm{hPa}$

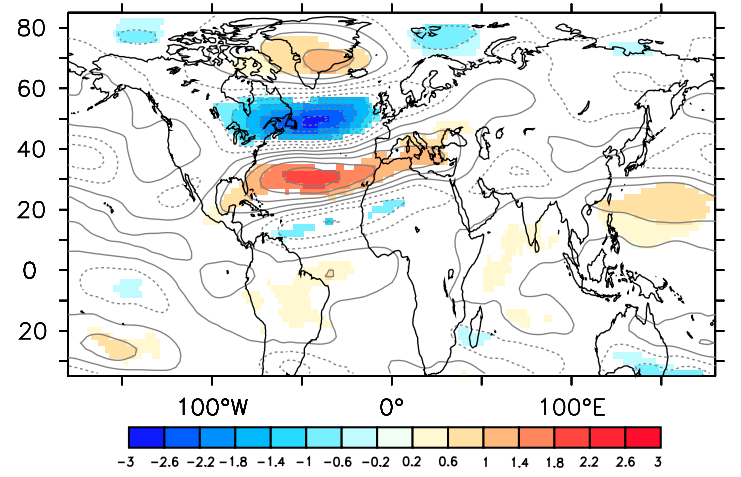

e) Eady Growth rate $850-\mathrm{hPa}$

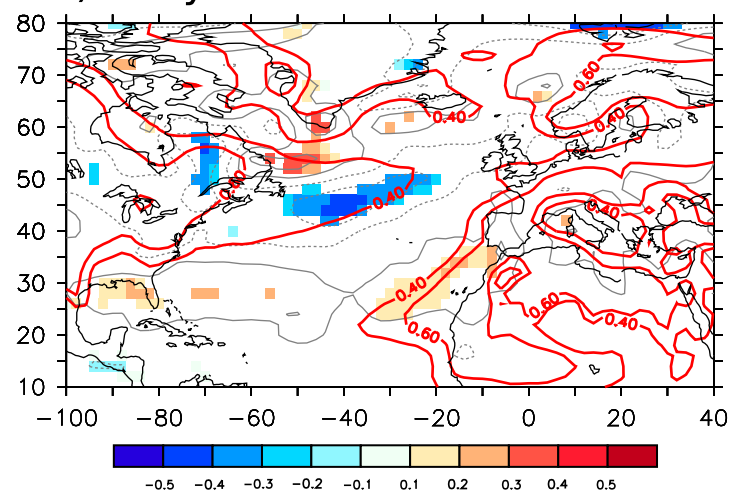

b) Wave Activity Flux

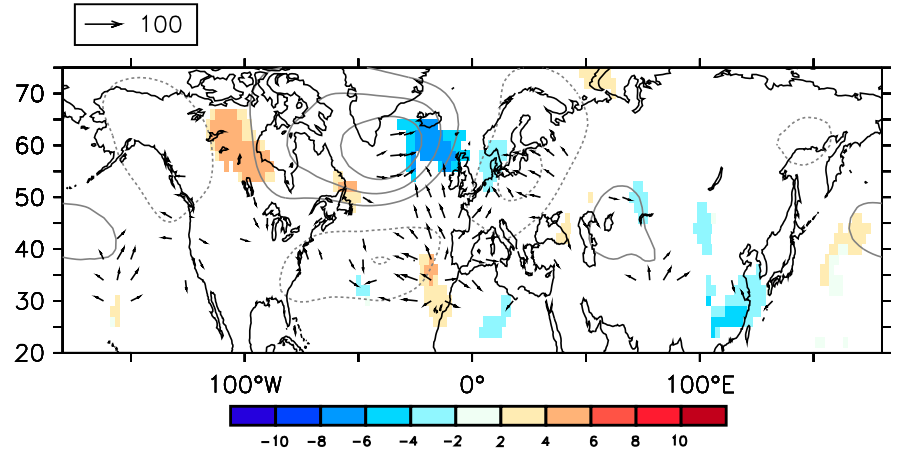

d) Zonal mean Geopotential Height

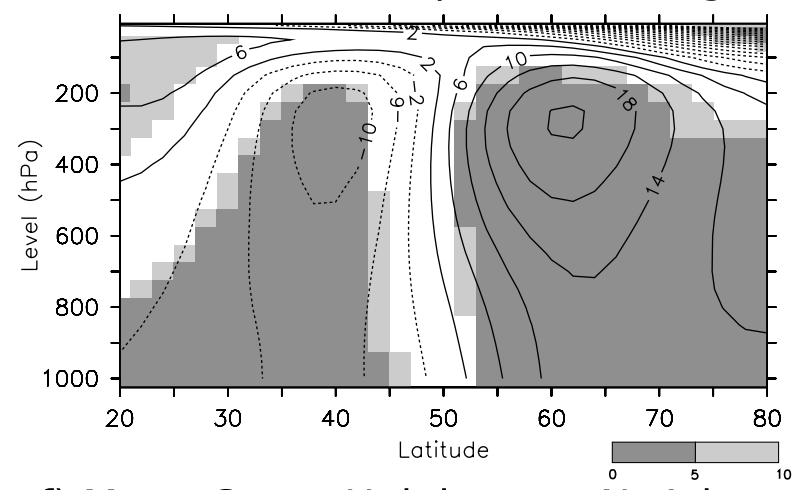

f) Mean Geop. Height over N. Atl

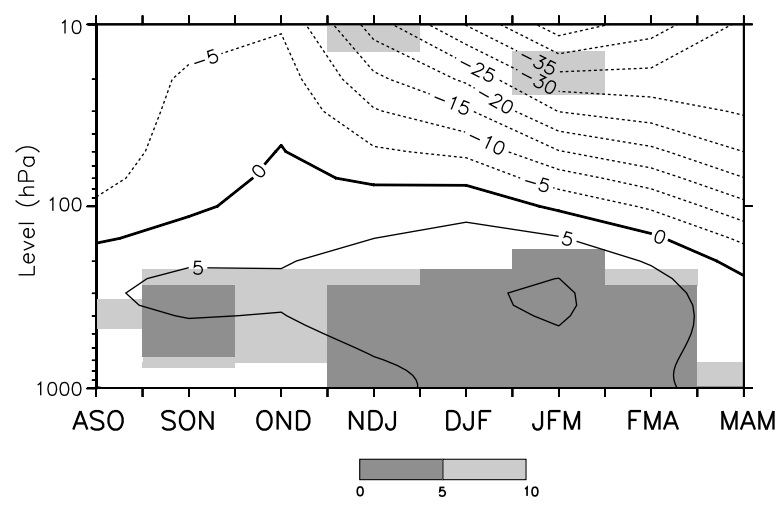

FIG. 15. Regression onto the MCA-LPF-SST 38 month earlier of (a) velocity potential at $200 \mathrm{hPa}\left(10^{-6} \mathrm{~s}^{-1}\right)$ and (b) wave activity flux, where vectors indicate the horizontal component of the wave activity flux at $300 \mathrm{hPa}\left(\mathrm{m}^{2} \mathrm{~s}^{-2}\right)$ exceeding $20 \mathrm{~m}^{2} \mathrm{~s}^{-2}$ in strength, colors indicate the vertical component of the wave activity flux at $500 \mathrm{hPa}\left(10^{-2} \mathrm{~m}^{2} \mathrm{~s}^{-2}\right)$, and contours indicate the zonal deviation of the $500-\mathrm{hPa}$ geopotential height anomalies (contour interval of $5 \mathrm{~m}$; zero contour omitted). (c) Zonal wind at $250 \mathrm{hPa}$ ( $\mathrm{m} \mathrm{s}^{-1}$ ). (d) Zonal-mean geopotential height $(\mathrm{m})$ in the Atlantic sector $\left(100^{\circ} \mathrm{W}-40^{\circ} \mathrm{E}\right)$. (e) Eady growth rate $\left(10^{-1}\right.$ day), with a red contour for climatology $\left(\right.$ day $\left.{ }^{-1}\right)$. (f) Regression of the averaged geopotential height over the polar North Atlantic ( $\left.\mathrm{m} ; 55^{\circ}-90^{\circ} \mathrm{N}, 100^{\circ} \mathrm{W}-40^{\circ} \mathrm{E}\right)$ from ASO to MAM onto the MCA-LPF-SST 3 yr earlier associated with the atmospheric response in JFM, so that the lag ranges from 31 (ASO) to 40 (MAM) months. The color shades are masked if the significance is above $5 \%$, except in (b), where it indicates a significance above $10 \%$. In (d),(f) the gray shades indicate the significance $(\%)$.

tripole is similar to the traditional SST tripole forced by the NAO during winter (see Fig. 6a). The atmospheric signal appears to be forced by both tropical and extratropical North Atlantic SSTs. There is also evidence of an influence of an NAH-like SST anomaly on the summer NAO, which seems to be primarily driven by midlatitude North Atlantic SSTs. The NAH is broadly similar to the North Atlantic tripole, but the subpolar SST anomaly is displaced eastward and the subtropical anomaly is more contracted, so that a crescent-shaped 
anomaly joins in the east the subpolar and the tropical poles (see Fig. 6c). During the fall and early winter, the NAH SST anomalies also have a strong influence on the atmosphere, primarily via extratropical SSTs. An SST warming (cooling) in the subpolar and the eastern tropical North Atlantic leads a negative (positive) phase of the NAO, as in Czaja and Frankignoul $(1999,2002)$. The response might be first induced by the surface changes in the western subpolar region, which alter the lower-tropospheric baroclinicity over the SST gradient anomalies and then act to modify the transient and stationary eddies. The positive eddy feedback would then lead to a large-scale equivalent barotropic signal (Peng et al. 2003; Deser et al. 2007).

We repeated our analysis, applying a small temporal smoothing to each variable in order to investigate the interannual-to-decadal relationship between ocean and atmosphere. The low-pass filtering reduces the amplitude of the intrinsic atmospheric fluctuations and does not affect seasonality, but it requires large lags to detect an oceanic influence, thus stressing the impact of persistent SST anomalies. It was found that an SST anomaly pattern almost identical to the AMO has a significant influence on the atmosphere in both summer and winter. The AMO anomalies (see Figs. 1 and 9b) also have a horseshoe shape but show larger subpolar SST anomalies and much smaller anomalies over the western subtropical North Atlantic compared to the NAH. During summer, the AMO primarily influences the lower troposphere and causes a warming over northeastern Europe, eastern North America, and Siberia and a cooling over the Mediterranean region, as found by Sutton and Hodson (2005). During winter, the AMO-like SST anomaly precedes a negative NAO in DJF and, more significantly, in JFM, which can be seen at least four winters in advance. There are some hints that the atmospheric response is primarily driven by SST forcing in the northern subtropics. The AMO-like SST pattern resembles the NAH SST anomaly, but for a much stronger subpolar lobe, presumably reflecting the strong SST persistence resulting from the large mixed layer depth in this region, SST anomaly reemergence, and the influence of low-frequency AMOC fluctuations (e.g., Knight et al. 2005; Gastineau and Frankignoul 2012). The atmospheric response was detected later in the season at low frequency. Indeed, the winter NAH SST anomalies have a larger persistence at low frequency than the late summer/fall NAH SST anomalies that precede at the seasonal scale the NAO in early winter. In addition, the atmospheric variability, which is largest in winter, is reduced by low-pass filtering, which enhances the signal-to-noise ratio. It may also be that the strengthened subpolar anomaly at low frequency favors a response later in the season. The influence of the AMO onto the atmosphere is similar to that in Peings and Magnusdottir (2014) or Ting et al. (2014), but our analysis is based on a weaker time filter so that causes and effects are better distinguished.

The ENSO influence had been removed prior to analysis and SST anomalies in the Indo-Pacific then remained below $0.2 \mathrm{~K}$, which suggests that other modes of variability from the tropical Indo-Pacific SSTs are unlikely to have played a role. This was confirmed by an MCA between the SST in the Indo-Pacific and the North Atlantic Z500, which was not able to retrieve any link between the two regions when the ocean leads. Moreover, we found no evidence in 20CR that Eurasian snow and Arctic sea ice cover were linked to the winter NAO response at interannual-to-decadal time scales, but a better dataset may be needed to reach firmer conclusions. The low-frequency winter atmospheric response is negligible in the stratosphere, which seems contradictory with Omrani et al. (2014), but the coupling between the stratosphere and the troposphere cannot be revealed in the 20CR (Paek and Huang 2012).

The cross-validated correlation found from the lowpass-filtered variables by removing successive sets of $5 \mathrm{yr}$ before performing the MCA and then using the MCA patterns to determine the amplitude of the middle year is 0.53 when SST leads by 38 months. Moreover, the SST time series explains $13 \%$ of the Z500 variance. Hence, our results suggest that there is some potential NAO predictability in winter at decadal time scales since the AMO-like SST anomalies are large in the subpolar region, where the decadal predictability of SST due to internal climate variability and the AMOC is largest in climate model hindcasts (e.g., Keenlyside et al. 2008; Branstator et al. 2012; Kirtman et al. 2014).

Acknowledgments. The research leading to these results has received funding from the European Union 7th Framework Programme (FP7 2007-2013) under Grant Agreement 308299. Support for the Twentieth Century Reanalysis Project dataset is provided by the U.S. Department of Energy Office of Science Innovative and Novel Computational Impact on Theory and Experiment (DOE INCITE) program and Office of Biological and Environmental Research (BER) and by the National Oceanic and Atmospheric Administration Climate Program Office.

\section{REFERENCES}

Barnston, A., and R. E. Livezey, 1987: Classification, seasonality and persistence of low-frequency circulation patterns. Mon. Wea. Rev., 115, 1083-1126, doi:10.1175/1520-0493(1987)115<1083: CSAPOL $>2.0 . \mathrm{CO} ; 2$. 
Booth, B. B., N. J. Dunstone, P. R. Halloran, T. Andrews, and N. Bellouin, 2012: Aerosols implicated as a prime driver of twentieth-century North Atlantic climate variability. Nature, 484, 228-232, doi:10.1038/nature10946.

Branstator, G., G. A. Meehl, M. Kimoto, J. R. Knight, M. Latif, and A. M. Rosati, 2012: Systematic estimates of initial value decadal predictability for six AOGCMs. J. Climate, 25, 18271846, doi:10.1175/JCLI-D-11-00227.1.

Bretherton, C. S., C. Smith, and J. M. Wallace, 1992: An intercomparison of methods for finding coupled patterns in climate data. J. Climate, 5, 541-560, doi:10.1175/ 1520-0442(1992)005<0541:AIOMFF>2.0.CO;2.

Brönnimann, S., E. Xoplaki, C. Casty, A. Pauling, and J. Luterbacher, 2007: ENSO influence on Europe during the last centuries. Climate Dyn., 28, 181-197, doi:10.1007/ s00382-006-0175-z.

Cassou, C., C. Deser, and M. A. Alexander, 2007: Investigating the impact of reemerging sea surface temperature anomalies on the winter atmospheric circulation over the North Atlantic. J. Climate, 20, 3510-3526, doi:10.1175/JCLI4202.1.

Cattiaux, J., and C. Cassou, 2013: Opposite CMIP3/CMIP5 trends in the wintertime northern annular mode explained by combined local sea ice and remote tropical influences. Geophys. Res. Lett., 40, 3682-3687, doi:10.1002/ grl.50643.

Cayan, D. R., 1992: Latent and sensible heat flux anomalies over the northern oceans: The connection to monthly atmospheric circulation. J. Climate, 5, 354-369, doi:10.1175/ 1520-0442(1992)005<0354:LASHFA > 2.0.CO;2.

Cohen, J., and J. Jones, 2011: A new index for more accurate winter predictions. Geophys. Res. Lett., 38, L21701, doi:10.1029/ 2011 GL049626.

Compo, G. P., and Coauthors, 2011: The Twentieth Century Reanalysis project. Quart. J. Roy. Meteor. Soc., 137, 1-28, doi:10.1002/qj.776.

Czaja, A., and C. Frankignoul, 1999: Influence of the North Atlantic SST on the atmospheric circulation. Geophys. Res. Lett., 26, 2969-2972, doi:10.1029/1999GL900613.

— and - 2002: Observed impact of Atlantic SST anomalies on the North Atlantic Oscillation. J. Climate, 15, 606-623, doi:10.1175/1520-0442(2002)015<0606:OIOASA > 2.0.CO;2.

de Coëtlogon, G., and C. Frankignoul, 2003: The persistence of winter sea surface temperature in the North Atlantic. J. Climate, 16, 1364-1377, doi:10.1175/1520-0442-16.9.1364.

Delworth, T. L., and R. J. Greatbatch, 2000: Multidecadal thermohaline circulation variability driven by atmospheric surface flux forcing. J. Climate, 13, 1481-1495, doi:10.1175/ 1520-0442(2000)013<1481:MTCVDB > 2.0.CO;2.

Deser, C., and A. S. Phillips, 2009: Atmospheric circulation trends, 1950-2000: The relative roles of sea surface temperature forcing and direct atmospheric radiative forcing. J. Climate, 22, doi:10.1175/2008JCLI2453.1.

_- R. A. Tomas, and S. Peng, 2007: The transient atmospheric circulation response to North Atlantic SST and sea ice anomalies. J. Climate, 20, 4751-4767, doi:10.1175/ JCLI4278.1.

—- M. A. Alexander, S. P. Xie, and A. S. Phillips, 2010: Sea surface temperature variability: Patterns and mechanisms. Аnnu. Rev. Mar. Sci., 2, 115-143, doi:10.1146/ annurev-marine-120408-151453.

DeWeaver, E., and S. Nigam, 2000: Zonal-eddy dynamics of the North Atlantic Oscillation. J. Climate, 13, 3893-3914, doi:10.1175/1520-0442(2000)013<3893:ZEDOTN>2.0.CO;2.
Dong, B., and R. T. Sutton, 2005: Mechanism of interdecadal thermohaline circulation variability in a coupled ocean-atmosphere GCM. J. Climate, 18, 1117-1135, doi:10.1175/JCLI3328.1.

Drévillon, M., L. Terray, P. Rogel, and C. Cassou, 2001: Mid latitude Atlantic SST influence on European winter climate variability in the NCEP reanalysis. Climate Dyn., 18, 331-344, doi:10.1007/s003820100178.

Enfield, D. B., A. M. Mestas-Nuñez, and P. J. Trimble, 2001: The Atlantic multidecadal oscillation and its relation to rainfall and river flows in the continental US. Geophys. Res. Lett., 28 , 2077-2080, doi:10.1029/2000GL012745.

Folland, C. K., A. W. Colman, D. P. Rowell, and M. K. Davey, 2001: Predictability of Northeast Brazil rainfall and realtime forecast skill, 1987-98. J. Climate, 14, doi:10.1175/ 1520-0442(2001)014<1937:PONBRA > 2.0.CO;2.

—, J. Knight, H. W. Linderholm, D. Fereday, S. Ineson, and J. W. Hurrell, 2009: The summer North Atlantic Oscillation: Past, present, and future. J. Climate, 22, 1082-1103, doi:10.1175/ 2008JCLI2459.1.

Frankignoul, C., 1979: Stochastic forcing models of climate variability. Dyn. Atmos. Oceans, 3, 465-479, doi:10.1016/ 0377-0265(79)90025-3.

__ and K. Hasselmann, 1977: Stochastic climate models. Part II. Application to sea-surface temperature anomalies and thermocline variability. Tellus, 29, 289-305, doi:10.1111/ j.2153-3490.1977.tb00740.x.

_ , and E. Kestenare, 2005: Observed Atlantic SST anomaly impact on the NAO: An update. J. Climate, 18, 4089-4094, doi:10.1175/JCLI3523.1.

— N. Sennéchael, Y. O. Kwon, and M. A. Alexander, 2011: Influence of the meridional shifts of the Kuroshio and the Oyashio Extensions on the atmospheric circulation. J. Climate, 24, 762-777, doi:10.1175/2010JCLI3731.1.

—, G. Gastineau, and Y. O. Kwon, 2013: The influence of the AMOC variability on the atmosphere in CCSM3. J. Climate, 26, 9774-9790, doi:10.1175/JCLI-D-12-00862.1.

— N. Sennéchael, and P. Cauchy, 2014: Observed atmospheric response to cold season sea ice variability in the Arctic J. Climate, 27, 1243-1254, doi:10.1175/JCLI-D-13-00189.1.

Franzke, C., S. Lee, and S. B. Feldstein, 2004: Is the North Atlantic Oscillation a breaking wave? J. Atmos. Sci., 61, 145-160, doi:10.1175/1520-0469(2004)061<0145: ITNAOA $>2.0 . \mathrm{CO} ; 2$.

Gastineau, G., and C. Frankignoul, 2012: Cold-season atmospheric response to the natural variability of the Atlantic meridional overturning circulation. Climate Dyn., 39, 37-57, doi:10.1007/ s00382-011-1109-y.

_ , F. D'Andrea, and C. Frankignoul, 2013: Atmospheric response to the North Atlantic Ocean variability on seasonal to decadal time scales. Climate Dyn., 40, 2311-2330, doi:10.1007/ s00382-012-1333-0.

Goldenberg, S. B., C. W. Landsea, A. M. Mestas-Nuñez, and W. M. Gray, 2001: The recent increase in Atlantic hurricane activity: Causes and implications. Science, 293, 474-479, doi:10.1126/ science. 1060040 .

Hasselmann, K., 1976: Stochastic climate models. Part I. Theory. Tellus, 28, 473-485, doi:10.1111/j.2153-3490.1976.tb00696.x.

Hoskins, B. J., and P. J. Valdes, 1990: On the existence of storm-tracks. J. Atmos. Sci., 47, 1854-1864, doi:10.1175/ 1520-0469(1990)047<1854:OTEOST>2.0.CO;2.

Hurrell, J. W., Y. Kushnir, G. Ottersen, and M. Visbeck, 2003: The North Atlantic Oscillation: Climatic Significance and Environmental Impact. Geophys. Monogr., Vol. 134, Amer. Geophys. Union, 279 pp. 
Iwasaka, N., and J. M. Wallace, 1995: Large scale air sea interaction in the Northern Hemisphere from a view point of variations of surface heat flux by SVD analysis. J. Meteor. Soc. Japan, 73, 781-794.

Keenlyside, N. S., M. Latif, J. Jungclaus, L. Kornblueh, and E. Roeckner, 2008: Advancing decadal-scale climate prediction in the North Atlantic sector. Nature, 453, 84-88, doi:10.1038/ nature 06921.

Kilbourne, K. H., T. M. Quinn, R. Webb, T. Guilderson, J. Nyberg, and A. Winter, 2008: Paleoclimate proxy perspective on $\mathrm{Ca}$ ribbean climate since the year 1751: Evidence of cooler temperatures and multidecadal variability. Paleoceanography, 23, PA3220, doi:10.1029/2008PA001598.

Kirtman, B., and Coauthors, 2014: Near-term climate change: Projections and predictability. Climate Change 2013: The Physical Science Basis, T. F. Stocker et al., Eds., Cambridge University Press, 953-1028.

Knight, J. R., R. J. Allan, C. K. Folland, M. Vellinga, and M. E. Mann, 2005: A signature of persistent natural thermohaline circulation cycles in observed climate. Geophys. Res. Lett., 32, L20708, doi:10.1029/2005GL024233.

- C. K. Folland, and A. A. Scaife, 2006: Climate impacts of the Atlantic multidecadal oscillation. Geophys. Res. Lett., 33, L17706, doi:10.1029/2006GL026242.

Knudsen, M. F., M. S. Seidenkrantz, B. H. Jacobsen, and A. Kuijpers, 2011: Tracking the Atlantic multidecadal oscillation through the last 8,000 years. Nat. Commun., 2, 178, doi:10.1038/ ncomms1186.

Krueger, O., F. Schenk, F. Feser, and R. Weisse, 2013: Inconsistencies between long-term trends in storminess derived from the 20CR reanalysis and observations. J. Climate, 26, 868-874, doi:10.1175/JCLI-D-12-00309.1.

Kushnir, Y., W. A. Robinson, I. Bladé, N. M. Hall, S. Peng, and R. Sutton, 2002: Atmospheric GCM response to extratropical SST anomalies: Synthesis and evaluation. J. Climate, 15, 2233-2256, doi:10.1175/1520-0442(2002)015<2233: AGRTES>2.0.CO;2.

Lau, N. C., 1988: Variability of the observed midlatitude storm tracks in relation to low-frequency changes in the circulation pattern. J. Atmos. Sci., 45, 2718-2743, doi:10.1175/ 1520-0469(1988)045<2718:VOTOMS $>2.0 . \mathrm{CO} ; 2$.

Lee, D. E., and M. Biasutti, 2014: Climatology and variability of precipitation in the Twentieth Century Reanalysis. J. Climate, 27, 5964-5981, doi:10.1175/JCLI-D-13-00630.1.

Lee, M. Y., and H. H. Hsu, 2013: Identification of the EurasianNorth Pacific multidecadal oscillation and its relationship to the AMO. J. Climate, 26, 8139-8153, doi:10.1175/ JCLI-D-13-00041.1.

Li, F., and H. Wang, 2013: Autumn sea ice cover, winter Northern Hemisphere annular mode, and winter precipitation in Eurasia. J. Climate, 26, 3968-3981, doi:10.1175/JCLI-D-12-00380.1.

Mann, M. E., 2008: Smoothing of climate time series revisited. Geophys. Res. Lett., 35, L16708, doi:10.1029/2008GL034716.

Marini, C., and C. Frankignoul, 2013: An attempt to deconstruct the Atlantic multidecadal oscillation. Climate Dyn., 43, 607625, doi:10.1007/s00382-013-1852-3.

Mathieu, P. P., R. T. Sutton, B. Dong, and M. Collins, 2004: Predictability of winter climate over the North Atlantic European region during ENSO events. J. Climate, 17, 1953-1974, doi:10.1175/1520-0442(2004)017<1953:POWCOT>2.0.CO;2.

Matsueda, M., 2011: Predictability of Euro-Russian blocking in summer of 2010. Geophys. Res. Lett., 38, L06801, doi:10.1029/ 2010 GL046557.
McCabe, G. J., M. A. Palecki, and J. L. Betancourt, 2004: Pacific and Atlantic Ocean influences on multidecadal drought frequency in the United States. Proc. Natl. Acad. Sci. USA, 101, 4136-4141, doi:10.1073/pnas.0306738101.

Mohino, E., S. Janicot, and J. Bader, 2011: Sahel rainfall and decadal to multi-decadal sea surface temperature variability. Climate Dyn., 37, 419-440, doi:10.1007/s00382-010-0867-2.

Nigam, S., B. Guan, and A. Ruiz-Barradas, 2011: Key role of the Atlantic multidecadal oscillation in 20th century drought and wet periods over the Great Plains. Geophys. Res. Lett., 38, L16713, doi:10.1029/2011GL048650.

Omrani, N. E., N. S. Keenlyside, J. Bader, and E. Manzini, 2014: Stratosphere key for wintertime atmospheric response to warm Atlantic decadal conditions. Climate Dyn., 42, 649-663, doi:10.1007/s00382-013-1860-3.

Paek, H., and H. P. Huang, 2012: A comparison of decadal-tointerdecadal variability and trend in reanalysis datasets using atmospheric angular momentum. J. Climate, 25, 4750-4758, doi:10.1175/JCLI-D-11-00358.1.

Peings, Y., and G. Magnusdottir, 2014: Forcing of the wintertime atmospheric circulation by the multidecadal fluctuations of the North Atlantic Ocean. Environ. Res. Lett., 9, 034018, doi:10.1088/1748-9326/9/3/034018.

_, E. Brun, V. Mauvais, and H. Douville, 2013: How stationary is the relationship between Siberian snow and Arctic Oscillation over the 20th century? Geophys. Res. Lett., 40, 183-188, doi:10.1029/2012GL054083.

Peng, S., W. A. Robinson, and S. Li, 2002: North Atlantic SST forcing of the NAO and relationships with intrinsic hemispheric variability. Geophys. Res. Lett., 29, doi:10.1029/ 2001GL014043.

,-- , and -2003 : Mechanisms for the NAO responses to the North Atlantic SST tripole. J. Climate, 16, 1987-2004, doi:10.1175/1520-0442(2003)016<1987:MFTNRT>2.0.CO;2.

Petoukhov, V., and V. A. Semenov, 2010: A link between reduced Barents-Kara sea ice and cold winter extremes over northern continents. J. Geophys. Res., 115, D21111, doi:10.1029/ 2009JD013568.

Rayner, N. A., D. E. Parker, E. B. Horton, C. K. Folland, L. V. Alexander, D. P. Rowell, E. C. Kent, and A. Kaplan, 2003: Global analyses of sea surface temperature, sea ice, and night marine air temperature since the late nineteenth century. J. Geophys. Res., 108, 4407, doi:10.1029/ 2002JD002670.

Sardeshmukh, P. D., and B. J. Hoskins, 1988: The generation of global rotational flow by steady idealized tropical divergence. J. Atmos. Sci., 45, 1228-1251, doi:10.1175/1520-0469(1988)045<1228: TGOGRF $>2.0 . \mathrm{CO} ; 2$.

Schneider, U., A. Becker, P. Finger, A. Meyer-Christoffer, B. Rudolf, and M. Ziese, cited 2011: GPCC full data reanalysis version 6.0 at $1.0^{\circ}$ : Monthly land-surface precipitation from rain-gauges built on GTS-based and historic data, doi:10.5676/ DWD_GPCC/FD_M_V6_100.

Sicre, M.-A., and Coauthors, 2008: Decadal variability of sea surface temperatures off north Iceland over the last 2000 years. Earth Planet. Sci. Lett., 268, 137-142, doi:10.1016/j.epsl.2008.01.011.

Smirnov, D., M. Newman, M. A. Alexander, Y.-O. Kwon, and C. Frankignoul, 2015: Investigating the local atmospheric response to a realistic shift in the Oyashio sea surface temperature front. J. Climate, 28, 1126-1147, doi:10.1175/JCLI-D-14-00285.1.

Stenchikov, G., A. Robock, V. Ramaswamy, M. D. Schwarzkopf, K. Hamilton, and S. Ramachandran, 2002: Arctic Oscillation response to the 1991 Mount Pinatubo eruption: Effects of 
volcanic aerosols and ozone depletion. J. Geophys. Res., 107, 4803, doi:10.1029/2002JD002090.

Sutton, R. T., and D. L. Hodson, 2005: Atlantic Ocean forcing of North American and European summer climate. Science, 309, 115-118, doi:10.1126/science.1109496.

Takaya, K., and H. Nakamura, 2001: A formulation of a phaseindependent wave-activity flux for stationary and migratory quasigeostrophic eddies on a zonally varying basic flow. J. Atmos. Sci., 58, 608-627, doi:10.1175/1520-0469(2001)058<0608: AFOAPI $>2.0 . \mathrm{CO} ; 2$.

Thompson, D. W., S. Lee, and M. P. Baldwin, 2003: Atmospheric processes governing the Northern Hemisphere annular mode/ North Atlantic Oscillation. The North Atlantic Oscillation: Climatic Significance and Environmental Impact, Geophys. Monogr., Vol. 134, Amer. Geophys. Union, 81-112.

Timlin, M. S., M. A. Alexander, and C. Deser, 2002: On the reemergence of North Atlantic SST anomalies. J. Climate, 15, 2707-2712, doi:10.1175/1520-0442(2002)015<2707:OTRONA > 2.0.CO;2.
Timmermann, A., M. Latif, R. Voss, and A. Grötzner, 1998: Northern Hemispheric interdecadal variability: A coupled air-sea mode. J. Climate, 11, 1906-1931, doi:10.1175/1520-0442-11.8.1906.

Ting, M., Y. Kushnir, R. Seager, and C. Li, 2009: Forced and internal twentieth-century SST trends in the North Atlantic. J. Climate, 22, 1469-1481, doi:10.1175/2008JCLI2561.1.

$-, \ldots, \ldots$, and ——, 2011: Robust features of Atlantic multidecadal variability and its climate impacts. Geophys. Res. Lett., 38, L17705, doi:10.1029/2011GL048712.

,$- \ldots$, and C. Li, 2014: North Atlantic multidecadal SST oscillation: External forcing versus internal variability. J. Mar. Syst., 133, 27-38, doi:10.1016/j.jmarsys.2013.07.006.

Watanabe, M., and M. Kimoto, 2000a: Atmosphere-ocean thermal coupling in the North Atlantic: A positive feedback. Quart. J. Roy. Meteor. Soc., 126, 3343-3369, doi:10.1002/qj.49712657017.

— and - 2000b: On the persistence of decadal SST anomalies in the North Atlantic. J. Climate, 13, 3017-3028, doi:10.1175/1520-0442(2000)013<3017:OTPODS>2.0.CO;2. 